\title{
Review
}

\section{Pt(IV) Prodrugs with NSAIDs as Axial Ligands}

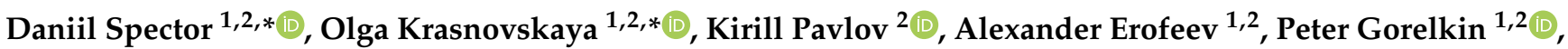 \\ Elena Beloglazkina ${ }^{2}$ and Alexander Majouga ${ }^{1,2,3}$ \\ 1 Department of Materials Science of Semiconductors and Dielectrics, National University of Science and \\ Technology (MISIS), Leninskiy Prospect 4, 101000 Moscow, Russia; erofeev@polly.phys.msu.ru (A.E.); \\ peter.gorelkin@gmail.com (P.G.); alexander.majouga@gmail.com (A.M.) \\ 2 Chemistry Department, Lomonosov Moscow State University, Leninskie Gory 1,3, 119991 Moscow, Russia; \\ kirill.pavlov2011@mail.ru (K.P.); beloglazki@mail.ru (E.B.) \\ 3 Mendeleev University of Chemical Technology of Russia, Miusskaya Ploshchad' 9, 125047 Moscow, Russia \\ * Correspondence: danspector@yandex.ru (D.S.); krasnovskayao@gmail.com (O.K.)
}

check for updates

Citation: Spector, D.; Krasnovskaya, O.; Pavlov, K.; Erofeev, A.; Gorelkin, P.; Beloglazkina, E.; Majouga, A. $\mathrm{Pt}(\mathrm{IV})$ Prodrugs with NSAIDs as Axial Ligands. Int. J. Mol. Sci. 2021, 22, 3817. https://doi.org/10.3390/ ijms22083817

Academic Editor: Nicola Margiotta

Received: 12 March 2021

Accepted: 31 March 2021

Published: 7 April 2021

Publisher's Note: MDPI stays neutral with regard to jurisdictional claims in published maps and institutional affiliations.

\begin{abstract}
A chemo-anti-inflammatory strategy is of interest for the treatment of aggressive cancers. The platinum (IV) prodrug with non-steroidal anti-inflammatory drugs (NSAIDs) as axial ligands is designed to efficiently enter tumor cells due to high lipophilicity and release the cytotoxic metabolite and NSAID intracellularly, thereby reducing side effects and increasing the therapeutic efficacy of platinum chemotherapy. Over the last 7 years, a number of publications have been devoted to the design of such $\mathrm{Pt}(\mathrm{IV})$ prodrugs in combination with anti-inflammatory chemotherapy, with high therapeutic efficacy in vitro and In vivo. In this review, we summarize the studies devoted to the development of $\mathrm{Pt}(\mathrm{IV})$ prodrugs with NSAIDs as axial ligands, the study of the mechanism of their cytotoxic action and anti-inflammatory activity, the structure-activity ratio, and therapeutic efficacy.
\end{abstract}

Keywords: platinum; prodrugs; NSAIDs

\section{Introduction}

Platinum-containing antineoplastic agents are effective anticancer drugs that are used in 50\% of all chemotherapy regimens in clinical practice [1]. Three FDA-approved platinumcontaining anticancer drugs have been applied around the world for decades: cisplatin, carboplatin, and oxaliplatin [2]. Also, a second generation drug, nedaplatin, is approved in Japan for the treatment of lung, esophageal, and head and neck cancers; lobaplatin is approved in China for the treatment of inoperable metastatic breast cancer and smallcell lung cancer [3]; and heptaplatin is approved in Korea for the treatment of stomach cancer [4].

$\mathrm{Pt}(\mathrm{II})$ coordination compounds easily undergo non-selective ligand substitution on the way to the tumor site, while approximately $90 \%$ of the administered cisplatin is deactivated in the bloodstream due to irreversible binding to albumin and other plasma proteins, with only $1 \%$ (or less) binding with the intended target (nuclear DNA) [5]. Protein binding to cisplatin leads to the formation of toxic metabolites that cause serious side effects such as kidney damage, nerve damage, and hearing loss [6]. Cisplatin was also reported to cause severe delayed emesis after 24 hours of administration [7]. The second-generation platinum anticancer drugs, carboplatin and oxaliplatin, are less toxic than cisplatin but show no improvement in potency or selectivity [8,9]. Various strategies have been suggested to improve the efficiency of platinum drugs [10]. One of the approaches to overcome these and the other well-known disadvantages of Pt(II)-based drugs, such as low bioavailability and rapidly emerging resistance, is to use $\mathrm{Pt}(\mathrm{IV})$ complexes as prodrugs. $\mathrm{Pt}(\mathrm{IV})$ have a low-spin octahedral $\mathrm{d}_{6}$ geometry and have the potential to overcome the disadvantages associated with platinum-containing chemotherapeutic agents [11]. The oxidation state of $\mathrm{Pt}(\mathrm{IV})$ provides an increased inertness of the coordination compounds compared to the $\mathrm{Pt}(\mathrm{II})$ complexes, and the conjugation of additional ligands in the axial position allows for both 
adjusting the lipophilicity and increasing the selectivity of the coordination compounds to tumor cells [12].

Chronic inflammation is an important therapeutic target in both the treatment of malignant neoplasms and drug development [13]. Various isoforms of cyclooxygenase (COX), such as COX-1 and COX-2, are markers of chronic inflammation, catalyzing the ratelimiting stage of prostaglandin formation, which plays a key role in the formation of the immune response [14]. Since COX-2 and prostaglandin-2 are involved in the inflammatory response, the suppression of apoptosis, and the formation of drug resistance, the inhibition of COX-2 can reduce inflammation and, as a result, reduce the rate of metastasis of malignant neoplasms [15]. Drug resistance is also associated with epithelial-mesenchymal transition (EMT), which is the transdifferentiation of epithelial cells into motile mesenchymal cells [16]. EMT-activated cells release matrix metalloproteinases (MMPs); the increased expression of MMPs contributes to the development of malignant neoplasms [17]. In addition, EMT transition is accompanied by the overexpression of COX-2, which can lead to immune evasion and tumor drug resistance [18].

Non-steroidal anti-inflammatory drugs (NSAIDs) are capable of inhibiting various isoforms of cyclooxygenase, which makes them a promising addition to existing chemotherapy regimens, both in view of their anti-inflammatory and analgesic effects, but also their ability to reduce the rate of metastasis and mount an immune response [19]. The development of $\mathrm{Pt}(\mathrm{IV})$ prodrugs with COX inhibitors in the axial position is a promising therapeutic approach due to the fact that the Pt(IV) prodrug's ability to bind COX-2 will increase the selectivity of prodrugs for tumor cells in comparison with classical $\mathrm{Pt}(\mathrm{II})$ drugs. Also, an increase in the lipophilicity of the $\mathrm{Pt}(\mathrm{IV})$ prodrug compared to the initial $\mathrm{Pt}(\mathrm{II})$ drugs significantly increases drug intracellular accumulation, thereby increasing its effectiveness and reducing side effects due to a decrease in the effective dose. Thus, the design and synthesis of $\mathrm{Pt}(\mathrm{IV})$ prodrugs modified with NSAID moieties will make it possible to obtain effective drugs with increased selectivity for tumor cells, higher efficacy compared to classical platinum-containing drugs, as well as an additional anti-inflammatory effect that provides a synergistic effect with chemotherapy and reduces side effects.

Since 2014, after the report of the cisplatin-based $\mathrm{Pt}(\mathrm{IV})$ prodrug with aspirin as the axial ligand, asplatin, which is capable of simultaneously releasing the NSAID aspirin and cisplatin by Pathak et al. [20], lots of publications have been devoted to the design of $\mathrm{Pt}(\mathrm{IV})$ prodrugs based on different platinum(II) drugs with non-steroidal anti-inflammatory drugs as axial ligands (Figure 1), and most of the prodrugs developed so far have demonstrated high therapeutic efficiency in vitro and In vivo. In this review, we have summarized the results obtained over the years, and examined the data obtained, the mechanisms of cytotoxic action, and the data from In vivo studies.

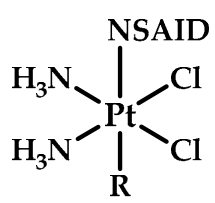<smiles>[R][P-]1([Y15])(N)NC2CCCCC2O1</smiles><smiles>[R][Te]([Y19])(N)(N)OC(=O)C1(C(=O)O)CCC1</smiles><smiles>[R][PH]([NH3+])(Cl)(Cl)NC1CCC2CCC1N2</smiles>

Figure 1. General structures of cisplatin-based, oxaliplatin-based, carboplatin-based, and kiteplatin-based Pt(IV) prodrugs with non-steroidal anti-inflammatory drugs (NSAIDs) as axial ligand(s).

In the first part of this review, we summarize dual-action Pt(IV) prodrugs with one or two NSAID moieties as axial ligand(s) (Table 1). In the second part of this review, we summarize unsymmetrical triple action $\mathrm{Pt}(\mathrm{IV})$ prodrugs with different bioactive axial ligands, including a study of the mechanism of their cytotoxic action, anti-inflammatory activity, the structure-activity ratio, and therapeutic efficacy. 
Table 1. Dual action platinum(IV) prodrugs with NSAIDs as axial ligand(s). DU145-androgen independent human prostate adenocarcinoma cells; HNSCC—Head and neck squamous cell carcinoma; MDA-MB-231—triple negative human breast adenocarcinoma; HCT-116 — human colon carcinoma; BEL7404—human hepatoma cell line; A2780—human ovarian carcinoma; MCF-7-human breast adenocarcinoma; CT-26-murine colorectal carcinoma.

\begin{tabular}{|c|c|c|c|c|c|c|}
\hline Compound & Pt(II) Drug & NSAID & $\begin{array}{l}\mathbf{R} \\
\text { (Second Axial } \\
\text { Position) }\end{array}$ & $\begin{array}{c}\text { IC }_{50} \text { (Tumor Cell } \\
\text { Type) }\end{array}$ & $\begin{array}{c}\text { In Vivo Studies } \\
\text { (Tumor, Dose, Tumor Growth } \\
\text { Suppression, Day of Treatment) }\end{array}$ & Reference \\
\hline 1 & Cisplatin & Aspirin & Hydroxyl & $8 \pm 3$ (DU145) & - & [20] \\
\hline 2 & Cisplatin & Indometacin & Indometacin & $\begin{array}{c}0.69(1483 \\
\text { HNSCC) }\end{array}$ & - & [21] \\
\hline 3 & Cisplatin & Ibuprofen & Ibuprofen & $\begin{array}{c}0.045(1483 \\
\text { HNSCC })\end{array}$ & & \\
\hline 4 & Oxaliplatin & Indometacin & Indometacin & $\begin{array}{c}0.55 \\
\text { (MDA-MB-231) }\end{array}$ & - & [22] \\
\hline 5 & Oxaliplatin & Ibuprofen & Ibuprofen & $\begin{array}{c}0.33 \\
\text { (MDA-MB-231) }\end{array}$ & & \\
\hline 6 & Kiteplatin & Ibuprofen & Ibuprofen & $\begin{array}{c}0.26 \pm 0.03 \\
(\mathrm{HCT} 116)\end{array}$ & - & [23] \\
\hline 7 & Cisplatin & Flurbiprofen & Flurbiprofen & $\begin{array}{c}1.4 \pm 1.1 \\
(B E L 7404)\end{array}$ & - & [24] \\
\hline 8 & Cisplatin & Ketoprofen & Acetyl & $\begin{array}{l}0.063 \pm 0.033 \\
(\mathrm{~A} 2780)\end{array}$ & - & [25] \\
\hline 9 & Cisplatin & Naproxen & Acetyl & $\begin{array}{l}0.045 \pm 0.033 \\
(\mathrm{~A} 2780)\end{array}$ & & \\
\hline 10 & Cisplatin & Naproxen & Hydroxyl & $\begin{array}{l}10.40 \pm 0.79 \\
(\mathrm{MCF}-7)\end{array}$ & & \\
\hline 11 & Carboplatin & Naproxen & Hydroxyl & $\begin{array}{l}9.12 \pm 0.63 \\
(\mathrm{MCF}-7)\end{array}$ & - & [26] \\
\hline 12 & Oxaliplatin & Naproxen & Hydroxyl & $\begin{array}{l}9.47 \pm 0.75 \\
(\mathrm{MCF}-7)\end{array}$ & & \\
\hline 13 & Cisplatin & Naproxen & Benzoic acid & $\begin{array}{c}3.92 \pm 0.42 \\
\text { (MCF-7) }\end{array}$ & & \\
\hline 14 & Cisplatin & Naproxen & Succinic acid & $\begin{array}{c}7.65 \pm 0.84 \\
(\mathrm{MCF}-7)\end{array}$ & & \\
\hline 15 & Cisplatin & Naproxen & Glutaric acid & $\begin{array}{c}8.73 \pm 0.89 \\
(\mathrm{MCF}-7)\end{array}$ & & \\
\hline 16 & Cisplatin & Naproxen & $\mathrm{Cl}$ & $0.2 \pm 0.1(\mathrm{CT}-26)$ & 17: & \\
\hline 17 & Oxaliplatin & Naproxen & $\mathrm{Cl}$ & $2.9 \pm 0.7(\mathrm{CT}-26)$ & CT-26 & \\
\hline 18 & Carboplatin & Naproxen & $\mathrm{Cl}$ & $26.1 \pm 8.6(\mathrm{CT}-26)$ & $4 \mathrm{mg} / \mathrm{kg}$ & [27] \\
\hline 19 & Oxaliplatin & Naproxen & Naproxen & $8.2 \pm 0.6(\mathrm{CT}-26)$ & $82.5 \%$ & \\
\hline 20 & Carboplatin & Naproxen & Naproxen & $27.3 \pm 5.7(\mathrm{~A} 549)$ & 15 days & \\
\hline 21 & Cisplatin & Naproxen & Naproxen & $\begin{array}{c}0.16 \pm 0.01 \\
(\text { MDA-MB-231) }\end{array}$ & $\begin{array}{c}\text { 21: } \\
\text { MDA-MB-231: }\end{array}$ & [28] \\
\hline 10 & Cisplatin & Naproxen & Hydroxyl & $\begin{array}{l}0.40 \pm 0.10 \\
(\mathrm{MCF}-7)\end{array}$ & $\begin{array}{c}1.5 \mathrm{mg} / \mathrm{kg} \\
92.8 \%\end{array}$ & \\
\hline 22 & Cisplatin & Etodolac & Etodolac & $\begin{array}{c}0.17 \pm 0.04 \\
(\mathrm{MCF}-7)\end{array}$ & $\begin{array}{l}15 \text { days } \\
\text { 22: } \\
\text { MCF-7; }\end{array}$ & [29] \\
\hline 23 & Cisplatin & Carprofen & Carprofen & $\begin{array}{l}0.95 \pm 0.04 \\
(\mathrm{MCF}-7)\end{array}$ & $\begin{array}{c}3 \mathrm{mg} / \mathrm{kg} \\
15 \text { days, } 60.6 \%\end{array}$ & \\
\hline 24 & Cisplatin & Sulindac & Sulindac & $\begin{array}{c}2.68 \pm 1.09 \\
(\mathrm{MCF}-7)\end{array}$ & & \\
\hline
\end{tabular}

\section{Dual-Action Pt(IV) Prodrugs with NSAID Axial Ligands}

\subsection{Aspirin}

In 2014, Pathak et al. designed a conjugate of one aspirin moiety with a platinum core named asplatin (or Platin-A) 1, which was the first reported Pt(IV) prodrug with an NSAID as an axial ligand [20] (Figure 2). Acetylsalicylic acid (aspirin) is able to bind irreversibly with COX-1 and COX-2 and reduce the severity of cisplatin therapy side effects such as ototoxicity and nephrotoxicity [30,31]. The synthesis of asplatin $\mathbf{1}$ was performed by the acylation of oxoplatin by aspirin anhydride. 


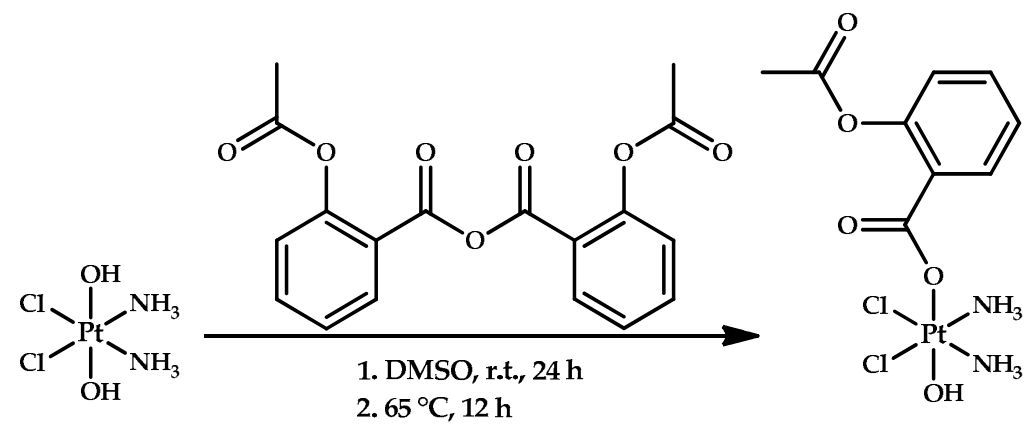

Figure 2. Synthesis of Platin A (asplatin) 1, the first cisplatin-based Pt(IV) prodrug with a NSAID as an axial ligand. DMSO -dimethylsulfoxide; r.t.-room temperature.

The ability of asplatin 1 to reduce was measured using cyclic voltammetry (CV) under two $\mathrm{pH}$ values. The change of $\mathrm{pH}$ value from 7.5 to a more acidic value of 6.4 was followed by $\mathrm{E}\left(\mathrm{Pt}^{+4} / \mathrm{Pt}^{+2}\right)$ reduction potential increase by $42 \mathrm{mV}$, thus allowing the authors to assume that prodrug 1 will be easily reduced in tumor tissues. In model conditions that mimic intracellular reduction, Platin-A 1 was incubated with sodium ascorbate and 2'deoxyguanosine $5^{\prime}$-monophosphate sodium salt hydrate (5'-GMP). Analysis of the reaction products by matrix-assisted laser desorption ionization (MALDI) mass-spectrometry (MS) showed the formation of Pt-GMP 2 bis adduct, $\left[\mathrm{Pt}\left(\mathrm{NH}_{3}\right)_{2}\left(5^{\prime}-\mathrm{GMP}\right)_{2}\right]$, thus proving the ability of Platin-A 1 reduction products to interact with guanosine bases in DNA [20].

The release of aspirin upon reduction of the prodrug was proved by HPLC; upon the reduction of prodrug $\mathbf{1}$ in the presence of sodium ascorbate, an increasing amount of aspirin and salicylic acid release from the prodrug was detected. This proves that platinum (IV) prodrugs are able to release active platinum(II) moieties and axial ligands in either pristine or metabolite form upon reduction [20].

A cytotoxicity assay demonstrated that the antiproliferative ability of asplatin was comparable to that of cisplatin (Table 2).

Table 2. Antiproliferative activity of cisplatin, asplatin 1, and an equimolar mixture of cisplatin + aspirin on the prostate tumor cell lines PC3 (androgen independent human prostate adenocarcinoma cells), DU145(androgen independent human prostate adenocarcinoma cells), and LNCaP (androgen-sensitive human prostate adenocarcinoma cells).

\begin{tabular}{cccc}
\hline \multirow{2}{*}{ Compound/Cell Line } & \multicolumn{3}{c}{ IC $_{\mathbf{5 0}, \boldsymbol{\mu M}}$} \\
\cline { 2 - 4 } & PC3 & DU145 & LNCaP \\
\hline Cisplatin & $14 \pm 4$ & $5 \pm 2$ & $15 \pm 1$ \\
Asplatin 1 & $15 \pm 5$ & $8 \pm 3$ & $12 \pm 1$ \\
Aspirin + Cisplatin (1:1) & $14 \pm 6$ & $4 \pm 1$ & $18 \pm 1$ \\
\hline
\end{tabular}

Asplatin 1 showed a similar ability to cisplatin to induce early apoptosis in tumor cells. Moreover, the ability of prodrug 1 to inhibit COX-1 and COX-2 was close to that of aspirin, which proves that prodrug 1 possesses both cytotoxic and anti-inflammatory properties. Asplatin 1 also suppressed tumor necrosis factor- $\alpha$ (TNF- $\alpha$ ) and interleukin (IL)-6, which causes an inflammatory response, while at the same time induced the secretion of the antiinflammatory cytokine IL-10. Thus, the conjugation of the NSAID aspirin with cisplatin resulted in a potent dual-action chemo-anti-inflammatory $\mathrm{Pt}(\mathrm{IV})$ prodrug capable of the simultaneous release of both anti-inflammatory and anticancer drugs, along with increased efficacy and reduced side effects, as compared to classical platinum chemotherapy [20]. 


\subsection{Ibuprofen}

Neumann et al. designed two Pt(IV) prodrugs with two moieties of indomethacin or ibuprofen in the axial position [21] (Figure 3). Prodrugs 2 and 3 were synthesized by reacting the corresponding acyl chloride with oxoplatin in acetone in the presence of pyridine.<smiles>NP(N)(O)(Cl)Cl</smiles>
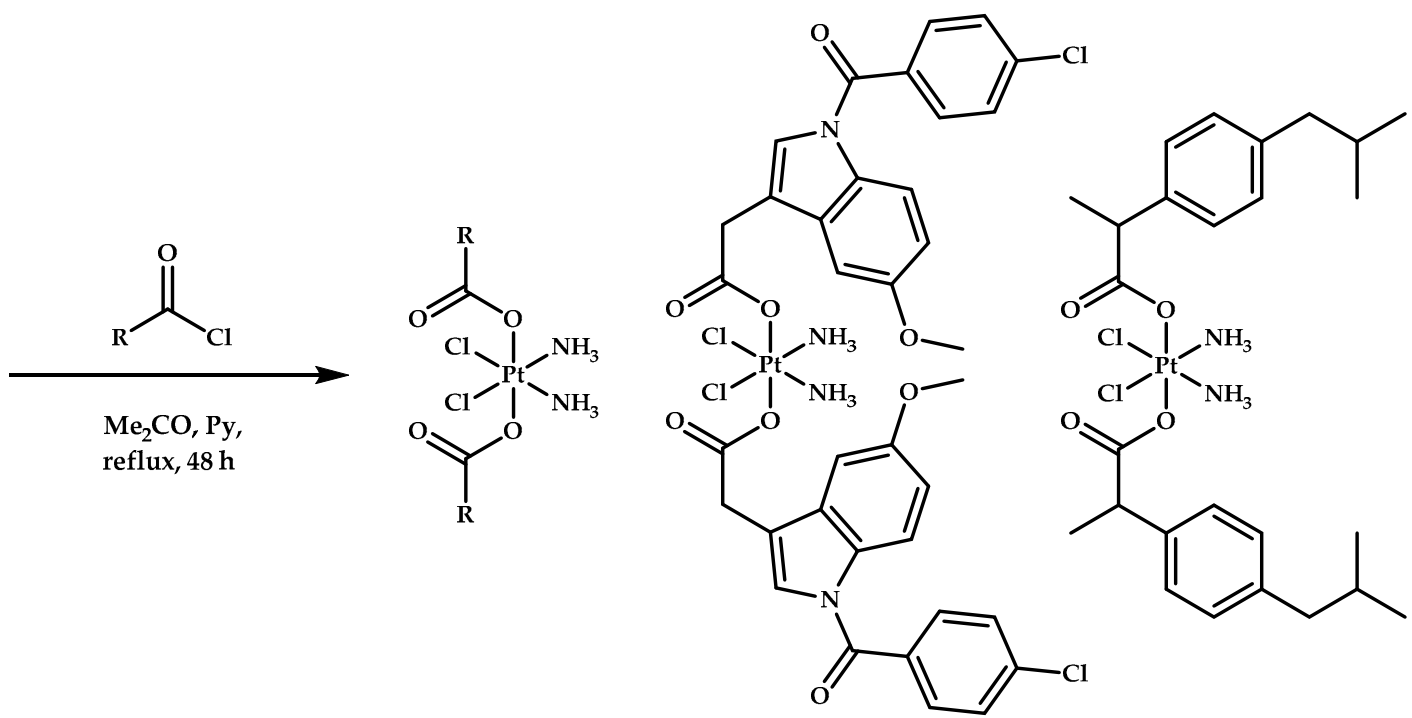

2

3

Figure 3. Synthesis of platinum(IV) prodrugs 2 and $\mathbf{3}$ with indomethacin and ibuprofen as the axial ligands.

The cyclic voltammetry assay showed a great difference between the reduction potentials of prodrugs 2 and 3 ( $-0.36 \mathrm{~V}$ and $-0.68 \mathrm{~V}$, respectively), which Neumann et al. suggested is probably due to the strong electron-withdrawing indole system and increased steric bulk of indomethacin. Thus, a weakened bond could probably facilitate ligand dissociation, resulting in poor stability. The stability of prodrugs 2 and 3 in a reducing environment was studied in the presence of ascorbic acid over three days. The release of axial ligands was detected by ${ }^{1} \mathrm{H}$ NMR. The release of ibuprofen and prodrug decay was observed as additional peaks in ${ }^{1} \mathrm{H}$ NMR and appeared in the $-\mathrm{CH}_{3}$ group region at $1.38 \mathrm{ppm}$ and the $-\mathrm{CH}_{2}-$ group region at $2.9 \mathrm{ppm}$. Approximately $40 \%$ of each drug was reduced during the experiment, which was evaluated by the authors as comparable with the clearance rate of platinum-based drugs from the body [21].

The COX-inhibiting ability of prodrugs 2 and 3 towards purified COX- 1 and COX-2 isoforms demonstrated that complex 2 was a highly selective inhibitor of COX-2, while complex 3 did not demonstrate any significant inhibiting activity on either isoform.

The antiproliferative activity of prodrugs $\mathbf{2}$ and $\mathbf{3}$ with cisplatin as a control was assessed on the colon cancer cell line HCT-116, the ovarian cancer cell line OVCAR3, the triple negative breast cancer cell line MDA-MB-231, and the head and neck squamous cell carcinoma cell line 1483 HNSCC via (3-(4,5-dimethylthiazol-2-yl)-2,5-diphenyltetrazolium bromide (MTT) assay (Table 3). Prodrugs 2 and 3 both showed antiproliferative activity surpassing that of cispaltin. It is also worth noting the extremely high activity of $\mathbf{3}$ towards MDA-MB-231 cells (cisplatin-resistant triple negative breast tumor cell line), where it was about 400-fold more toxic than cisplatin [21]. 
Table 3. Antiproliferative activity of cisplatin and platinum(IV) prodrugs 2 and 3 on HCT-116 (colorectal carcinoma), OVCAR3 (ovarian cancer), MDA-MB-231 (triple negative breast cancer), and 1483 HNSCC (head and neck squamous cell carcinoma) cell lines. The ability of cells to express cyclooxygenase-2 (COX-2) is indicated by "-" (non-expressing), "+" (expressing), "++" (strongly expressing).

\begin{tabular}{ccccc}
\hline \multirow{2}{*}{ Compound/Cell Line } & \multicolumn{4}{c}{ IC $_{\mathbf{5 0}}, \boldsymbol{\mu M}$} \\
\cline { 2 - 5 } & HCT-116 & OVCAR3 & MDA-MB-231 & $\mathbf{1 4 8 3}$ HNSCC \\
\hline COX-2 expression & - & + & + & ++ \\
\hline Cisplatin & 12 & 2.07 & 20 & 2 \\
$\mathbf{2}$ & 1.1 & 2.2 & 1.65 & 0.69 \\
$\mathbf{3}$ & 0.065 & 0.13 & 0.05 & 0.045 \\
\hline
\end{tabular}

Neumann et al. also designed oxaliplatin-based prodrugs 4 and 5 with indomethacin and ibuprofen as axial ligands [22]. Prodrugs 4 and 5 were obtained following the procedure utilized for synthesis of coordination compounds 2 and 3 , by the reaction of oxaliplatin with the corresponding acid chloride [21] (Figure 4).

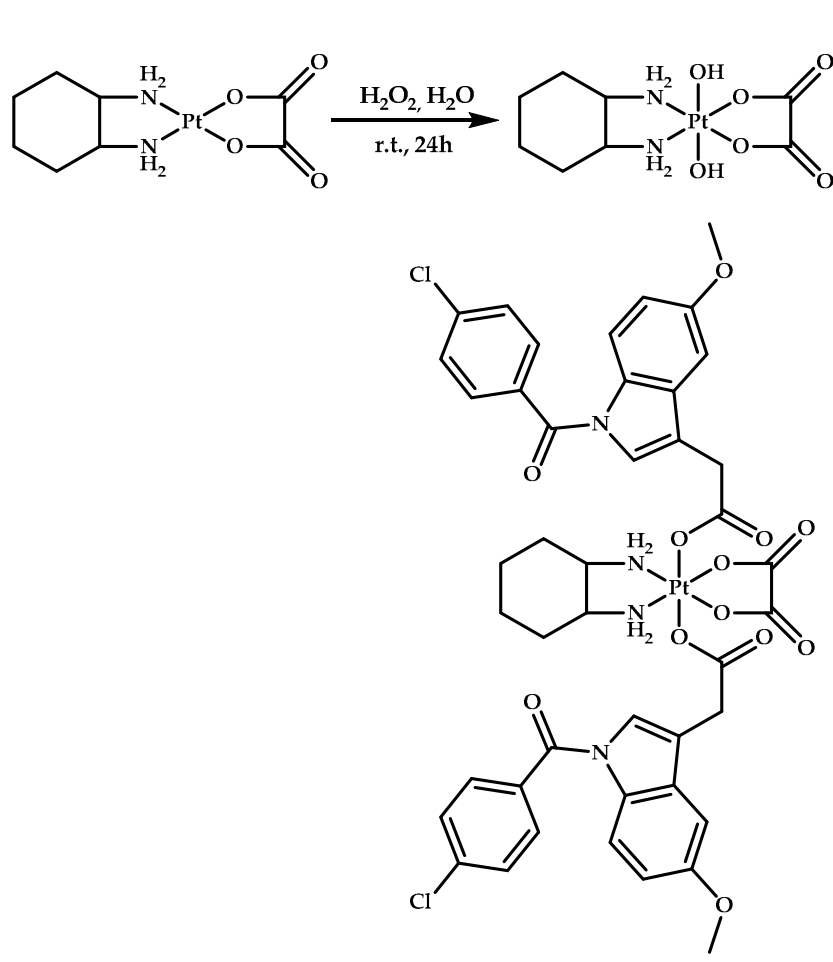

4

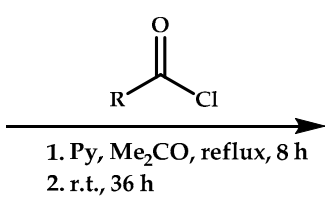<smiles>[Z]C(=O)O[Te](N)(NC1CCCCC1)(OC(C)=O)OC(=O)C(=O)O</smiles>

Figure 4. Synthesis of oxaliplatin-based platinum(IV) prodrugs 4 and 5 with indomethacin and ibuprofen as axial ligands.

Cyclic voltammetry was used to evaluate how easily prodrugs 4 and 5 could be reduced, since both too high and too low reduction potentials are detrimental to the activity of the complexes [32,33]. The reduction potentials obtained by CV experiments were compared to those obtained for cispaltin-based prodrugs 2 and 3 [21]. Contrary to the reduction potentials of prodrugs 2 and 3, in the case of prodrugs 4 and 5, no significant difference in reduction potential was observed $(-0.52 \mathrm{~V}$ and $-0.56 \mathrm{~V}$, respectively).

The ability of prodrugs 4 and 5 to inhibit cyclooxygenases was studied on purified isoforms of ovine COX-1 and murine COX-2. Neither of the isoforms were inhibited by ibuprofen-containing complexes 3 or 5 . However, while prodrug 2 with indomethacin in the axial position acts as a selective COX-2 inhibitor, its oxaliplatin analogue 4 demonstrated 
selectivity towards COX-1 and no activity against COX-2. Docking studies for prodrugs 2 and $\mathbf{4}$ were carried out to gain insight into the differences in binding of prodrugs 2 and $\mathbf{4}$ to COX-2. The results suggest that compound 4 cannot bind to COX-2 due to the constricted entrance in the COX-2 active site, which prevents the bulky oxaliplatin equatorial ligands of 4 from accessing the enzyme. The high inhibitory activity of prodrug 2 towards the COX-2 isoform is attributed to the additional activity of the second indomethacin moiety, while only one moiety of indomethacin in prodrug 4 interacts with the enzyme active site [22].

The cytotoxicity of complexes 4 and 5 was evaluated by MTT assay on HCT 116 (colorectal adenocarcinoma) and MDA-MB-231 (triple negative breast adenocarcinoma) cells (Table 4). Both prodrugs $\mathbf{4}$ and $\mathbf{5}$ showed sub-micromolar activity towards MDAMB-23 cells, while prodrug 5 demonstrated much lower $\mathrm{IC}_{50}$ values than prodrug 4 on HCT-116 cells $(0.31 \mu \mathrm{M}$ and $1.3 \mu \mathrm{M}$, respectively). However, both complexes 4 and 5 were less potent than cisplatin-based prodrug 3 with ibuprofen axial ligands. Cellular accumulation of prodrugs $\mathbf{2}-\mathbf{5}$ was studied via ICP-MS on HCT-116 and MDA-MB-231 cell lines (Table 5). Interestingly, no direct correlation between cytotoxicity and intracellular accumulation of prodrugs $\mathbf{2}-\mathbf{5}$ was found, as intracellular platinum accumulation in both HCT-116 and MDA-MB-231 cells for the most potent drug (3) was lower than for its less potent oxaliplatin analogue (5) and the cisplatin-indomethacin complex (2). The trend in platinum accumulation cannot be solely attributed to the lipophilicity of prodrugs 2-5; indomethacin is more lipophilic than ibuprofen ( $\log \mathrm{P}$ values are 4.27 and 3.5, respectively), however, no correlation between axial ligands and cellular uptake of prodrugs $\mathbf{2 - 5}$ was observed [22].

Table 4. Antiproliferative activity of oxaliplatin-based platinum(IV) prodrugs $\mathbf{4}$ and $\mathbf{5}$ and cisplatin on HCT-116 (colorectal carcinoma) and MDA-MB-231 (triple negative breast adenocarcinoma) cell lines. The ability of cells to express cyclooxygenase-2 (COX-2) is indicated by "-" (non-expressing), "+" (expressing).

\begin{tabular}{ccc}
\hline \multirow{2}{*}{ Compound/Cell Line } & \multicolumn{2}{c}{ IC $_{\mathbf{5 0}, \boldsymbol{\mu M}}$} \\
\cline { 2 - 3 } & HCT-116 & MDA-MB-231 \\
\hline COX-2 expression & - & + \\
Cisplatin & 12 & 20 \\
$\mathbf{4}$ & 1.3 & 0.55 \\
$\mathbf{5}$ & 0.31 & 0.33 \\
\hline
\end{tabular}

Table 5. Cellular accumulation of prodrugs $2-5$ and cisplatin ( $\mu \mathrm{g} \mathrm{Pt} / 10^{6}$ cells) on HCT-116 (colorectal carcinoma) and MDA-MB-231 (triple negative adenocarcinoma) cell lines.

\begin{tabular}{cll}
\hline & & \multicolumn{1}{c}{ Cellular Uptake, $\boldsymbol{\mu g}$ Pt/10 $\mathbf{6}^{\mathbf{6}}$ Cells } \\
\hline Compound/Cell line & HCT-116 & MDA-MB-231 \\
\hline Cisplatin & $0.008 \pm 0.001$ & $0.013 \pm 0.009$ \\
$\mathbf{2}$ & $0.26 \pm 0.04$ & $0.4 \pm 0.1$ \\
$\mathbf{3}$ & $0.096 \pm 0.007$ & $0.17 \pm 0.03$ \\
$\mathbf{4}$ & $0.014 \pm 0.001$ & $0.033 \pm 0.009$ \\
$\mathbf{5}$ & $0.18 \pm 0.01$ & $0.27 \pm 0.03$ \\
\hline
\end{tabular}

Curci et al. designed kiteplatin-based Pt(IV) prodrug 6 with two ibuprofen moieties as axial ligands [23]. The prodrug was obtained by the acylation of oxidized kiteplatin by the acid chloride of ibuprofen (Figure 5). The structure of the resulting complex was confirmed by thorough analysis of multiple NMR experiments, including 2D COSY spectrum and $\left[{ }^{1} \mathrm{H}_{-}{ }^{13} \mathrm{C}\right]-\mathrm{HSQC} 2 \mathrm{D}$ NMR. ${ }^{195} \mathrm{Pt}$ NMR showed the presence a single peak, confirming the formation of only one platinum complex. 


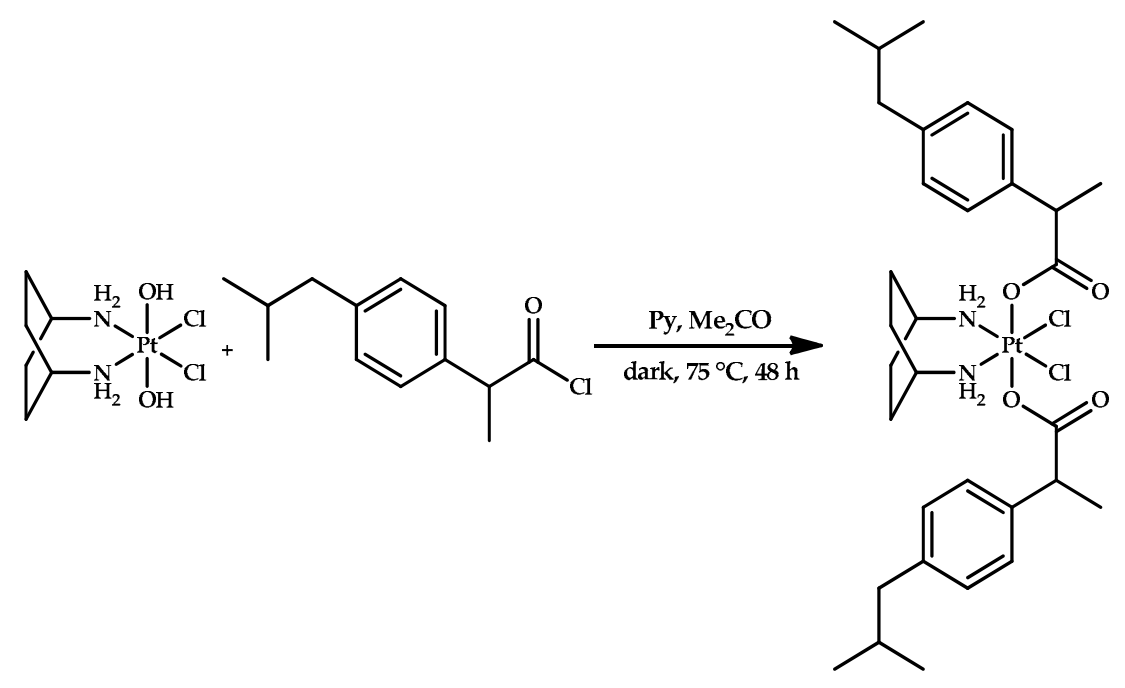

6

Figure 5. Synthesis of kiteplatin-based platinum(IV) prodrug 6 with two ibuprofen moieties as axial ligands.

To determine the stability of prodrug 6 , the $\mathrm{CV}$ electrochemical curves were recorded on a glassy carbon electrode. The determined reduction potential was found to be $-0.93 \mathrm{~V}$ and is compatible to the potentials of similar platinum(IV) coordination compounds [34]. The cytotoxicity of the compound 6 was studied on non-COX-expressing colorectal carcinoma cell lines. Prodrug 6 showed submicromolar IC $\mathrm{I}_{50}$ values, which was up to 42 -fold higher than platinum(II) drugs in the assay (Table 6).

Table 6. Antiproliferative activity of kiteplatin, cisplatin, ibuprofen, and platinum prodrug 6 on HCT15 (human colon carcinoma) and HCT116 (colon adenocarcinoma) cells.

\begin{tabular}{cll}
\hline & & IC $_{\mathbf{5 0},} \boldsymbol{\mu M}$ \\
\hline Compound/Cell Line & HCT15 & HCT116 \\
\hline $\mathbf{6}$ & $0.45 \pm 0.04$ & $0.26 \pm 0.03$ \\
Kiteplatin & $11 \pm 1$ & $7 \pm 1$ \\
Cisplatin & $17 \pm 2$ & $11 \pm 1$ \\
Ibuprofen & $>800$ & $708 \pm 8$ \\
\hline
\end{tabular}

\subsection{Flurbiprofen}

Tan et al. designed a cisplatin-based prodrug 7 with two flurbiprofen moieties in axial positions [24]. Synthesis of the compound was performed by the reaction of oxoplatin with flurbiprofen acid chloride in tetrahydrofuran (THF) (Figure 6). The formation of the complex was confirmed by observing the shift of the $-\mathrm{CH}_{3}$ methyl group from $1.41 \mathrm{ppm}$ in free flurbiprofen to $1.38 \mathrm{ppm}$ in the ${ }^{1} \mathrm{H}$ NMR spectrum of prodrug 7 . The reduction potential obtained by $\mathrm{CV}$ was $-0.68 \mathrm{~V}$ at $\mathrm{pH} 7.4$, which allowed the authors to assume that prodrug 7 is capable of reduction in a cellular environment.

The stability of prodrug 7 in the reducing environment was assessed in the presence of ascorbic acid as a reductant and showed complete decay of the complex within 48 hours, as determined by HPLC. To establish whether the $\mathrm{Pt}(\mathrm{IV})$ prodrug can release the $\mathrm{Pt}(\mathrm{II})$ DNA-binding moiety, compound 7 was incubated with ascorbic acid in the presence of $2^{\prime}$-deoxyguanosine $5^{\prime}$-monophosphate sodium salt hydrate (5-GMP), a nucleotide base of DNA. Analysis of the products by ESI-MS showed the formation of bifunctional Pt(II)/GMP adduct $\left[\mathrm{Pt}\left(\mathrm{NH}_{3}\right)_{2}\left(5^{\prime}-\mathrm{GMP}\right)_{2}\right]^{+}$with the observed $m / z$ of 922.46 . Thus, platinum(IV) prodrug 7 is capable of releasing cisplatin in reducing environments, which then binds to DNA [34]. 


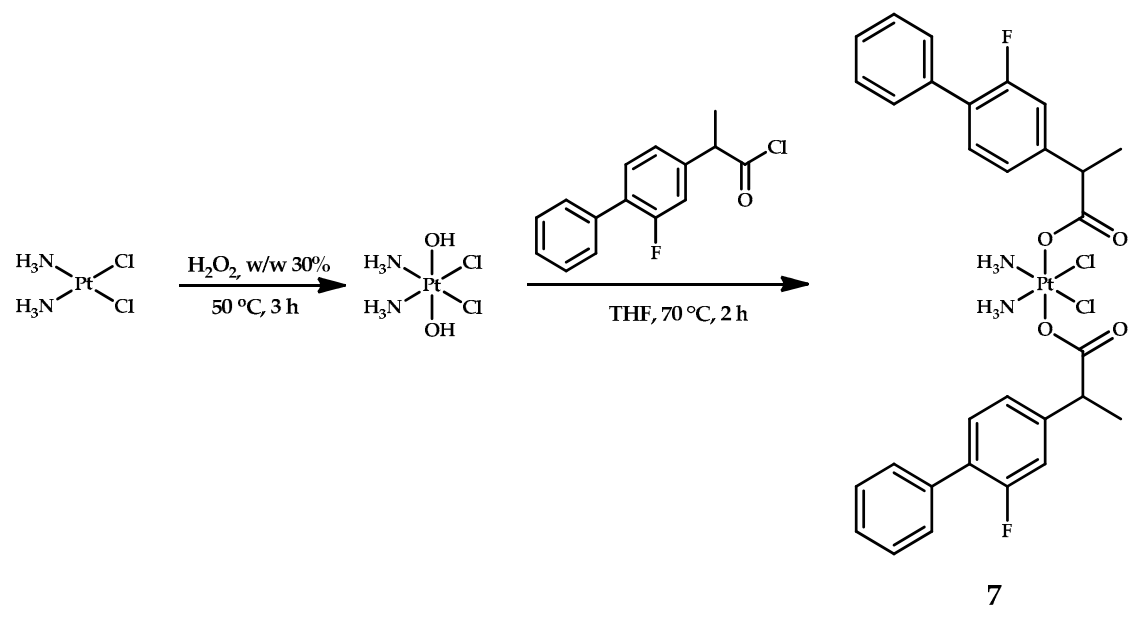

Figure 6. Synthesis of cisplatin-based prodrug 7 with two flurbiprofen moieties as axial ligands.

The cytotoxicity of prodrug 7 was evaluated by MTT assay (Table 7). The $\mathrm{IC}_{50}$ values of complex 7 were up to 82 -fold lower than for cisplatin and the equimolar mixture of cisplatin and flurbiprofen. It is worth noting that prodrug 7 showed activity against the cisplatinresistant cell line A549-DDP. Complex 7 was equally active on both cisplatin-sensitive and cisplatin-resistant A- 549 cells $(2.7 \mu \mathrm{M}$ and $2.5 \mu \mathrm{M}$, respectively), while cisplatin showed an almost 3-fold decrease in activity (7.4 $\mu \mathrm{M}$ for A549 and $20.03 \mu \mathrm{M}$ for A549-DDP). Cellular platinum accumulation was determined in BEL7404, BEL7404-CP20, and SW480 cells after 6 hours of incubation with $10 \mu \mathrm{M}$ of prodrug 7 , cisplatin, and an equimolar mixture of cisplatin and flurbiprofen. Platinum content in cells incubated with prodrug 7 was 21 - to 57-fold more than with cisplatin; DNA platination was 5- to 11-fold more for prodrug 7 than for cisplatin [23].

Table 7. Antiproliferative activity of Pt(IV) prodrug 7 on SW480 (colon adenocarcinoma), PC-3 (prostate adenocarcinoma), PANC-1 (pancreatic cancer), A549, A549-DDP (lung carcinoma), BEL7404 (liver carcinoma), and BEL7404-CP20 (cisplatinresistant liver carcinoma) cell lines.

\begin{tabular}{cccccccc}
\hline \multirow{2}{*}{ Compound/Cell Line } & \multicolumn{9}{c}{ IC $_{50}, \mu M$} \\
\cline { 2 - 8 } & SW480 & PC-3 & PANC-1 & A549 & A549-DDP & BEL7404 & BEL7404-CP20 \\
\hline Cisplatin & $49 \pm 1.1$ & $21.2 \pm 1.1$ & $14.4 \pm 1.1$ & $7.4 \pm 1.0$ & $20.03 \pm 1.1$ & $14.7 \pm 1.1$ & $>50$ \\
Cisplatin-Flurbiprofen (1:2) & $29.6 \pm 1.0$ & $22.4 \pm 1.1$ & $11.1 \pm 1.1$ & $7.1 \pm 1.0$ & $21.1 \pm 1.2$ & $18.1 \pm 1.0$ & $>50$ \\
7 & $0.6 \pm 1.1$ & $3.4 \pm 1.0$ & $3.4 \pm 1.1$ & $2.7 \pm 1.1$ & $2.5 \pm 1.1$ & $1.4 \pm 1.1$ & $3.1 \pm 1.1$ \\
\hline
\end{tabular}

An opalescence and the Tyndall effect of prodrug 7 stock solution was observed; thus, dynamic light scattering (DLS) analysis was conducted which showed that in solution, prodrug 7 formed nanoparticles with a diameter of $115.3 \mathrm{~nm}$. The formation of nanoparticles was further proved by scanning electron microscopy (SEM), transition electrone microscopy (TEM) and atomic force microscopy (AFM). The obtained results led the authors to the assumption that the difference in cellular uptake between prodrug 7 and cisplatin is due to nanoparticle formation [23].

\subsection{Naproxen}

Ravera et al. synthesized platinum(IV) prodrugs 8 and 9 based on cisplatin with two NSAIDs, naproxen and ketoprofen, in the axial positions (Figure 7) [25]. As a reference compound, asplatin 1 was chosen and synthesized as well. Asplatin 1 was prepared as described by Pathak et al. [20]. Prodrugs 8 and 9 were prepared by the acylation of $\left[\mathrm{Pt}\left(\mathrm{NH}_{3}\right)_{2}(\mathrm{Cl})_{2}(\mathrm{OH})(\mathrm{OAc})\right]$ by the corresponding acid chloride. 


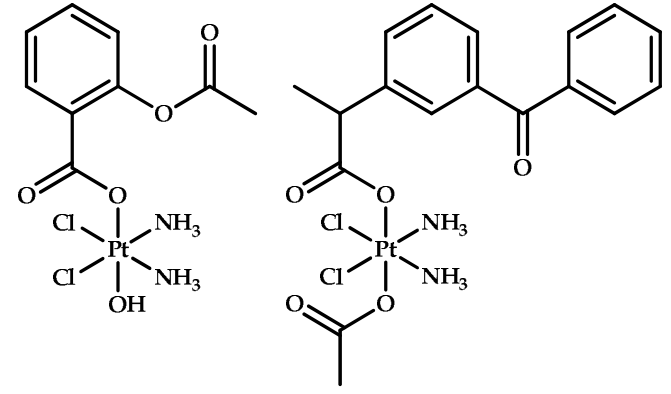

1
8<smiles>COc1ccc2cc(C(C)C(=O)O[I+](N)(N)(Cl)(Cl)OC(C)=O)ccc2c1</smiles>

9

Figure 7. Asplatin $\mathbf{1}$ and cisplatin-based platinum(IV) prodrugs $\mathbf{8}$ and $\mathbf{9}$ with ketoprofen and naproxen as axial ligands.

The lipophilicities of all three Pt(IV) prodrugs 1, 8 and 9 were evaluated using RPHPLC (Table 8). The logarithm of the RP-HPLC capacity factor k' usually correlates with the octanol/water partition coefficient [35]. The obtained $\log \mathrm{k}^{\prime}$ values for prodrugs $\mathbf{1 , 8}$ and 9 follows the same trend as for their corresponding NSAIDs. Asplatin $\mathbf{1}$ was found to be the least lipophilic, while 9 was the most lipophilic coordinating compound.

Table 8. Antiproliferative activity of cisplatin-based prodrugs 1, 8 and 9 on A549 (lung carcinoma), HT-29 (colon cancer), HCT 116 (colon adenocarcinoma), SW480 (colorectal cancer), A2780 (ovarian cancer), and MSTO-21 (malignant pleural mesothelioma) cell lines.

\begin{tabular}{|c|c|c|c|c|c|c|c|}
\hline \multirow{4}{*}{ Compound/Cell Line } & & \multicolumn{6}{|c|}{$\mathrm{IC}_{50}, \mu \mathrm{M}$} \\
\hline & & A549 & HT-29 & HCT 116 & MSTO-211H & SW480 & A2780 \\
\hline & \multirow{2}{*}{$\log k^{\prime}$} & \multicolumn{6}{|c|}{ COX Expression } \\
\hline & & ++ & ++ & + & - & - & - \\
\hline Cisplatin & -0.5 & $3.60 \pm 0.90$ & $2.72 \pm 0.39$ & $3.05 \pm 0.28$ & $1.33 \pm 0.35$ & $2.27 \pm 0.12$ & $0.46 \pm 0.11$ \\
\hline Oxaliplatin & -0.28 & $0.74 \pm 0.25$ & $0.92 \pm 0.08$ & $1.16 \pm 0.09$ & $1.01 \pm 0.55$ & $0.48 \pm 0.02$ & $0.171 \pm 0.008$ \\
\hline 1 & -0.32 & $6.40 \pm 2.7$ & $4.42 \pm 0.21$ & $1.50 \pm 0.083$ & $1.74 \pm 0.21$ & $0.217 \pm 0.07$ & $0.552 \pm 0.123$ \\
\hline 8 & 0.14 & $0.825 \pm 0.388$ & $0.486 \pm 0.235$ & $0.184 \pm 0.088$ & $0.198 \pm 0.035$ & $0.0948 \pm 0.023$ & $0.063 \pm 0.033$ \\
\hline 9 & 0.18 & $0.486 \pm 0.075$ & $0.313 \pm 0.186$ & $0.149 \pm 0.076$ & $0.161 \pm 0.040$ & $0.0844 \pm 0.0287$ & $0.045 \pm 0.016$ \\
\hline
\end{tabular}

The cytotoxicity of compounds 1, 8 and 9 was evaluated via MTT assay using both cyclooxygenase (COX)-expressing and non-COX-expressing cell lines (Table 8).

The results of the MTT assay demonstrated the significant antiproliferative activity of coordination compounds $\mathbf{8}$ and $\mathbf{9}$, which were up to 13-fold more toxic than asplatin $\mathbf{1}$ and up to 20-fold more toxic than cisplatin. No correlation between COX-2 expression and cytotoxicity was found. Based on the results of the MTT assay, lipophilicity can be assumed to be the main factor for prodrug cytotoxic activity, as the most lipophilic complex 9 is the most toxic, while the least lipophilic compound (cisplatin) has the highest $\mathrm{IC}_{50}$ values on nearly all cell lines [25].

In order to confirm the relationship between cytotoxicity and lipophilicity, the accumulation ratio (AR) was evaluated as the ratio between intra- and extracellular platinum concentration. Cells were incubated with $10 \mu \mathrm{M}$ of cisplatin and prodrugs 1, 8 and 9 for $4 \mathrm{~h}$. The most lipophilic prodrugs 8 and 9 demonstrated higher ARs than the less lipophilic cisplatin and asplatin 1 with AR values of 14 . AR values of platinum(IV) prodrugs 8 and 9 were 14 and 12, respectively, while cisplatin and Platin-A 1 demonstrated AR values of 2 and 1, respectively. The presence of lipophilic moieties in axial positions enhances the ability to penetrate the cellular membrane, leading to increased platinum uptake and, consequently, antiproliferative activity [36]. 
To confirm the assumption that the mechanism of the toxicity of prodrugs 8 and 9 is COX-independent, a RT-qPCR analysis was carried out. Two cell lines, one with high COX-2 expression (A-549) and one with low COX-2 expression (HCT-116), were chosen. Five genes were chosen to study the influence of prodrugs 8,9 , cisplatin, naproxen, and ketoprofen: Bcl-2 family genes that regulate apoptosis, COX-2, and NSAID-activated gene NAG-1. The pro-apoptotic proteins BAD (BCL2 associated agonist of cell death) and BAX (Bcl-2associated $X$ protein) were upregulated in the presence of all three platinum compounds in both cell lines, while the anti-apoptotic gene BCL-2 was downregulated. There is evidence that BAX upregulation promotes apoptotic activity through caspase activation [37]. COX-2 expression was upregulated by all compounds $(\mathbf{1}, \mathbf{8}, \mathbf{9}$, cisplatin, naproxen and ketoprofen) on the low COX-expressing cells HCT-116. The NAG-1 gene, which is involved in antiproliferative activity [38], was expressed by prodrugs 8,9 and cisplatin on both cell lines, including HCT-116, in which little to no COX-2 activity was observed.

To sum up, the antiproliferative activity of platinum(IV) prodrugs 8 and 9 was shown to occur through a COX-independent pathway, with lipophilicity being the key factor determining the efficiency of these compounds.

In another study devoted to the synthesis of $\mathrm{Pt}(\mathrm{IV})$ prodrugs with naproxen in axial positions, Tolan et al. designed six platinum-naproxen prodrugs derived from three Food and Drug Administration (FDA)-approved platinum(II) drugs [26] (Figure 8). Prodrugs 10-12 with a cisplatin, carboplatin and oxaliplatin core, respectively, were obtained by the reaction of oxoplatin with the N-hydroxysuccinimide (NHS)-ester of naproxen. Platinum prodrugs 13-16 with benzoic acid, succinic acid, glutaric acid and moieties, respectively, were synthesized by the reaction of complex $\mathbf{1 0}$ with the anhydride of the corresponding acid. Such an approach to the design of unsymmetrical platinum(IV) prodrugs allowed these authors to finely tune the properties of the resulting complex [39]. The second axial ligand of the platinum(IV) prodrugs 13-15 was varied to alter the resulting lipophilicities of the platinum(IV) prodrugs.

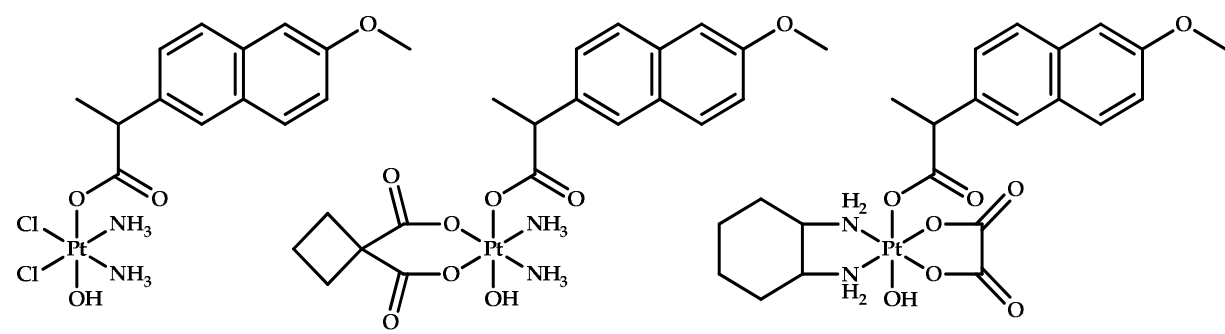

10<smiles>COc1ccc2cc(C(C)C(=O)O[V](N)(N)(Cl)(Cl)OC(=O)c3ccccc3)ccc2c1</smiles>

13<smiles>COc1ccc2cc(C(C)C(=O)OP(N)(N)(Cl)OC(=O)CCC(=O)O)ccc2c1</smiles>

14
12

Figure 8. Naproxen-containing mono-carboxylated platinum(IV) prodrugs based on cisplatin 10, carboplatin 11 and oxaliplatin 12 and di-carboxylated 13-15. 
The antiproliferative activity of prodrugs 10-15 was evaluated by MTT assay on the breast cancer cell line MCF-7 and the triple negative breast adenocarcinoma cell line MDA-MB-231 (Table 8). The cytotoxicity of all prodrugs on the MCF-7 cell line was 1.5- to 2-fold higher than that of cisplatin. The results of the MTT assay indicate an 11- to 30-fold difference between the $\mathrm{IC}_{50}$ values of cisplatin and compounds 10-15. It is worth noting that prodrug 13, with the most lipophilic benzoate ligand in the axial position, showed the lowest $\mathrm{IC}_{50}$ values among all prodrugs tested (10-15) [26].

Cell death mode was assessed by fluorescent staining of MCF-7 and MDA-MB-231 cells incubated with the most active $\mathrm{Pt}(\mathrm{IV})$ prodrug 13 . The results obtained indicate that prodrug 13 induces necrosis and apoptosis (early and late, combined) of 30.56\% and $22.68 \%$ cells, respectively, in MCF-7 cells, and $12.98 \%$ and $36.21 \%$, respectively, in MDA-MB-231 cells.

Another series of naproxen-containing platinum(IV) prodrugs was obtained by Chen et al. [27] (Figure 9). The focus of this study was the combined action of naproxen as an inhibitor of both cyclooxygenase-2 (COX-2) and matrix metalloproteinases (MMPs) and the impact of COX and MMP inhibition on the cytotoxic activity of $\mathrm{Pt}(\mathrm{IV})$ prodrugs.<smiles>COc1ccc2cc(C(C)C(=O)O[I+](N)(N)OC(=O)C3(C(=O)O[P+](N)(N)Cl)CCC3)ccc2c1</smiles>

16 17<smiles>COC1=CC=C2C=C(C=C1)C(C)C(=O)O[Pb](N[N+]1(OC(=O)C(C)c3ccc4cc(OC)ccc4c3)OC(=O)C(=O)O1)(OC(=O)C(C)c1ccc3cc(OC)ccc3c1)NC1CCCCC21</smiles>

19 18<smiles>COc1ccc2cc(C(C)C(=O)O[I+](N)(OC(=O)C(C)c3ccc4cc(OC)ccc4c3)OC(=O)C3(C(=O)O)CCC3)ccc2c1</smiles>

20

Figure 9. Naproxen-containing platinum(IV) prodrugs based on cisplatin 16, carboplatin 17 and oxaliplatin 18 and di-carboxylated complexes based on oxaliplatin 19 and carboplatin 20.

The antiproliferative activity of complexes 16-20 was evaluated by MTT assay on four malignant cell lines: A549, A549R (cisplatin-sensitive and cisplatin-resistant lung carcinoma, respectively), SKOV-3 (ovarian cancer), and CT-26 (colon cancer) in comparison with LO-2 (a human normal liver cell line) (Table 9). Prodrugs 19 and 20, with two naproxen moieties in axial positions, showed lesser activity than the corresponding mono-substituted complexes 17 and 18, respectively. The selectivity index (SI) was defined as the ratio of $\mathrm{IC}_{50}$ values obtained on the normal cell line $\mathrm{LO}-2$ to the average of the $\mathrm{IC}_{50}$ values obtained on tumor cells. Cisplatin and cisplatin-based prodrug 16 showed the worst SIs of 0.5 and 0.2 , respectively, while the best SI values of 1.0 and 1.5 were demonstrated by the dualnaproxen complexes 18 and 19, respectively. The most potent compound, 17, demonstrated higher activity than cisplatin on the cisplatin-resistant cell line A549R [27]. 
Table 9. Antiproliferative activity of cisplatin-, carboplatin-, oxaliplatin-based and platinum(IV) prodrugs 16-20 on A549, A549R (cisplatin-sensitive and cisplatin-resistant lung carcinoma, respectively), SKOV-3 (ovarian cancer), CT-26 (colon cancer), and LO-2 (human normal liver) cell lines. Selectivity index (SI) $=\mathrm{IC}_{50}(\mathrm{LO}-2) /$ average $\mathrm{IC}_{50}$ values.

\begin{tabular}{|c|c|c|c|c|c|c|}
\hline \multirow{2}{*}{ Compound/Cell Line } & \multicolumn{6}{|c|}{$\mathrm{IC}_{50}, \mu \mathrm{M}$} \\
\hline & A549 & A549R & SKOV-3 & CT-26 & LO-2 & $\mathrm{SI}^{\mathrm{a}}$ \\
\hline Cisplatin & $4.8 \pm 0.6$ & $15.1 \pm 1.1$ & $2.5 \pm 0.4$ & $0.3 \pm 0.1$ & $3.0 \pm 0.7$ & 0.5 \\
\hline Oxaliplatin & $8.4 \pm 2.2$ & $7.3 \pm 1.7$ & $9.4 \pm 2.3$ & $2.30 \pm 0.3$ & $3.6 \pm 0.5$ & 0.5 \\
\hline Carboplatin & $79.6 \pm 18.4$ & $60.6 \pm 14.7$ & $38.1 \pm 9.6$ & $46.2 \pm 11.4$ & $70.7 \pm 16.3$ & - \\
\hline 16 & $2.2 \pm 0.3$ & $19.7 \pm 2.5$ & $14.4 \pm 0.7$ & $0.2 \pm 0.1$ & $1.9 \pm 0.4$ & 0.2 \\
\hline 17 & $5.2 \pm 0.5$ & $4.8 \pm 0.3$ & $8.5 \pm 0.1 .6$ & $2.9 \pm 0.7$ & $4.8 \pm 0.8$ & 0.9 \\
\hline 18 & $47.2 \pm 6.9$ & $62.2 \pm 16.7$ & $26.0 \pm 5.5$ & $26.1 \pm 8.6$ & $39.9 \pm 9.8$ & 1.5 \\
\hline 19 & $10.2 \pm 1.0$ & $12.0 \pm 0.4$ & $11.3 \pm 0.8$ & $8.2 \pm 0.6$ & $15.3 \pm 2.5$ & 0.5 \\
\hline 20 & $27.3 \pm 5.7$ & $83.0 \pm 16.4$ & $48.9 \pm 7.5$ & $48.9 \pm 8.4$ & $26.3 \pm 4.7$ & 0.8 \\
\hline
\end{tabular}

Overexpressed levels of matrix metallopeptidase-9 (MMP-9) are associated with cancer invasion, metastasis, and inflammation In vivo [40]. The MMP-9 inhibitory activity of prodrug 17 was evaluated by immunohistochemical staining using slices of CT-26 mice tumors in comparison with the effect of oxaliplatin and saline. Compound $\mathbf{1 7}$ showed significant inhibition of MMP-9 expression (6.8\%), while oxaliplatin inhibition level was $8.1 \%$, in accordance with the literature data [41]. The observed difference in inhibitory activity is associated with the presence of the naproxen moiety in prodrug 17 . However, despite high inhibitory activity towards MMP-9 expression, prodrug 17 showed low COXinhibiting ability.

The therapeutic efficacy of prodrug 17 was assessed In vivo using a CT-26 (colon cancer) tumor model. The inhibition of tumor growth after treatment with prodrug 17 was at the level of cisplatin and oxaliplatin $\left(317 \pm 119 \mathrm{~mm}^{3}, 390 \pm 162 \mathrm{~mm}^{3}\right.$, and $477 \pm 223 \mathrm{~mm}^{3}$, respectively).

Recently, Jin et al. described two cisplatin-based naproxen-containing platinum(IV) prodrugs [28]. Two highly potent cisplatin prodrugs with one (NP, 10) or two (DNP, 21) naproxen moieties in the axial position were obtained (Figure 10). Prodrug 10 was already described by Tolan et al. [26] and synthesized following a similar procedure, while compound 21 was prepared by the reaction of oxoplatin with an excess of naproxen in the presence of 2 -(1H-benzotriazole-1-yl)-1,1,3,3-tetramethylaminium tetrafluoroborate (TBTU) and $\mathrm{Et}_{3} \mathrm{~N}$ in $\mathrm{N}, \mathrm{N}$-dimethylformamide (DMF).
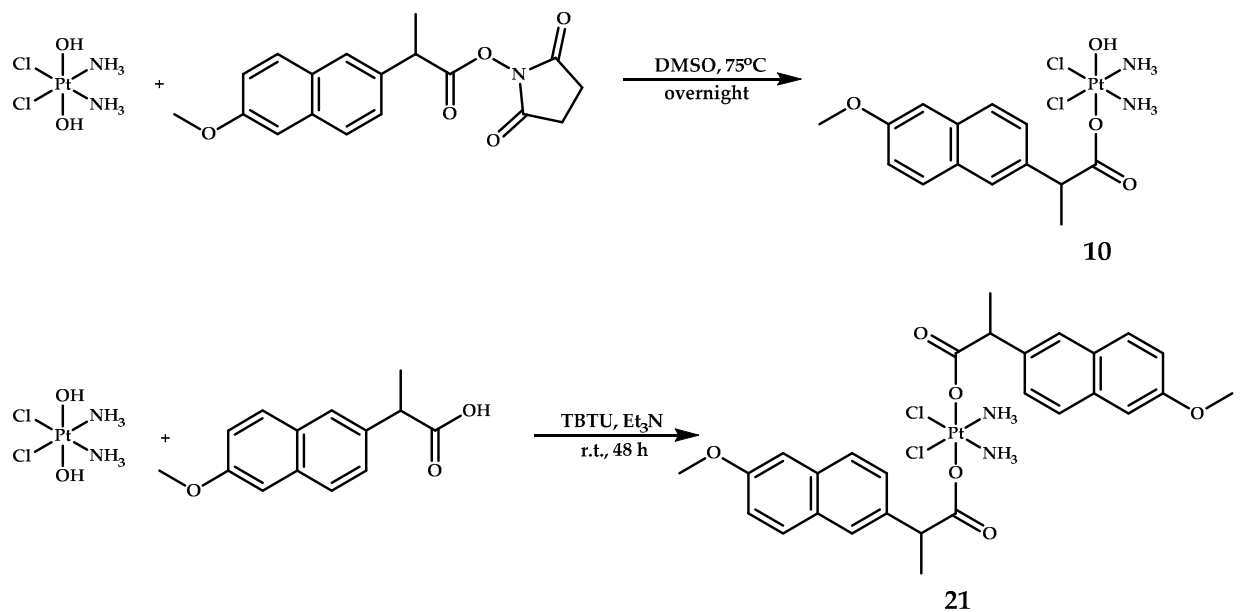

Figure 10. Synthesis of cisplatin-based monocarboxylated platinum(IV) prodrug $\mathbf{1 0}$ and dicarboxylated platinum(IV) prodrug 21 with one or two moieties of naproxen in axial positions, respectively. 
Both prodrugs 10 and $\mathbf{2 1}$ demonstrated outstanding antiproliferative activity towards the breast cancer cell lines MCF-7, MDA-MB-231 and MDA-MB-435 after 48 hours of incubation (Table 10). For prodrug 21, $\mathrm{IC}_{50}$ values varied from 0.34 to $0.17 \mu \mathrm{M}$, which is up to 187 -fold more than that of cisplatin, while prodrug 10 showed $\mathrm{IC}_{50}$ values from 1.11 to $0.4 \mu \mathrm{M}$. It is worth noting that the $\mathrm{IC}_{50}$ values obtained by Jin et al. for prodrug $10 \mathrm{differ}$ significantly from the data reported by Tolan et al.; in particular, for the MCF-7 breast cancer cell line, $\mathrm{IC}_{50}$ values for prodrug 10 in the study by Jin et al. are 26-fold higher, and for the MDA-MB-231 triple negative breast adenocarcinoma cell line, $\mathrm{IC}_{50}$ values are 21-fold higher than in the paper by Tolan et al. (Table 8) [28].

Table 10. Antiproliferative activity of cisplatin, equimolar mixtures of cisplatin and naproxen, and platinum(IV) prodrugs 21 and 10 on MCF-7 (breast cancer), MDA-MB-231 (triple negative breast adenocarcinoma), and MDA-MB-435 (triple negative breast adenocarcinoma) cell lines.

\begin{tabular}{cccc}
\hline \multirow{2}{*}{ Compound/Cell Line } & \multicolumn{3}{c}{ IC $_{\mathbf{5 0}, \boldsymbol{\mu M}}$} \\
\cline { 2 - 4 } & MCF-7 & MDA-MB-231 & MDA-MB-435 \\
\hline $\mathbf{2 1}$ & $0.17 \pm 0.04$ & $0.16 \pm 0.01$ & $0.34 \pm 0.09$ \\
$\mathbf{1 0}$ & $0.40 \pm 0.10$ & $0.81 \pm 0.02$ & $1.11 \pm 0.06$ \\
Cisplatin & $4.00 \pm 1.00$ & $29.98 \pm 1.10$ & $8.34 \pm 0.49$ \\
Cisplatin + Naproxen & $7.00 \pm 2.00$ & $>64$ & $>32$ \\
Cisplatin + 2 Naproxen & $5.18 \pm 2.80$ & $>64$ & $>32$ \\
Naproxen & $>64$ & $>64$ & $>64$ \\
\hline
\end{tabular}

The intracellular accumulation/distribution of prodrugs 10, 21, and cisplatin was assessed by ICP-MS assay in MCF-7 cells after incubation with $0.2 \mu \mathrm{M}$ of each complex for 24 hours. The overall platinum content was 65- and 11-fold higher for cells incubated with 21 and 10, respectively, than for cells incubated with cisplatin. However, less than 5\% of platinum accumulated in the nucleus of cells incubated with both prodrugs, as most of the platinum was found in the cytosol and cell membrane.

The stability of prodrugs $\mathbf{1 0}$ and $\mathbf{2 1}$ in a reducing environment was assessed in a model solution in the presence of ascorbic acid or glutathione. While complex 10 showed complete degradation after 3 hours, complex 21 was still stable after 72 hours of incubation. An additional experiment in solution in the presence of $5^{\prime}$-GMP was conducted to verify the ability of prodrug 21 to form covalent adducts with DNA bases; no Pt-GMP or Pt-GMP 2 were detected by ESI-MS after 6 days of incubation. This led Jin et al. to the assumption that complex 21 acts not as a prodrug, but as a whole complex that binds to DNA in a non-covalent manner [28].

Cell cycle arrest, as studied by flow cytometry, showed that prodrug $\mathbf{2 1}$ arrested the cell cycle of MCF-7 cells mostly in the S phase (87\% at $0.2 \mu \mathrm{M}$ incubation), while prodrug $\mathbf{1 0}$ arrested the cell cycle at the G2 and S phases. Further studies of prodrug 21's influence on the inflammatory response showed that it can greatly suppress COX-2 and programmed death-ligand 1 (PD-L1) expression in breast cancer cells, thus leading to suppressed tumor evasion from the immune system [42]. The expression of interleukins IL-1 $\beta$ and IL-6, which are crucial for the formation of an inflammatory response [43], was also greatly reduced by prodrug 21.

The antitumor activity of both prodrugs was studied In vivo using mouse xenografts bearing MDA-MB-231 tumor cells. After therapy with $1.5 \mathrm{mg} / \mathrm{kg}$ of prodrug 21 for 15 days, the tumor volume was only $66.35 \pm 26.07 \mathrm{~mm}^{3}$ (92.8\% tumor growth inhibition), while after treatment with the same dose of cisplatin and saline, this value was $660 \pm 68$ and $926 \pm 71 \mathrm{~mm}^{3}$, respectively. Prodrug 10 was less efficient than prodrug 21 (75.5\% tumor growth inhibition), but still inhibited tumor growth better than cisplatin (227 \pm 71 and $660 \pm 68 \mathrm{~mm}^{3}$ tumor volume, respectively). No significant change in body weight was observed for the mice in all series [28].

Thus, 21 is a highly potent platinum(IV) prodrug capable of significantly suppressing tumor growth and inflammatory response. 


\subsection{Etodolac, Sulindac, and Carprofen}

Three cisplatin-based platinum(IV) prodrugs with the FDA-approved NSAIDs etodolac, sulindac, and carprofen (22-24) were designed by Song et al. (Figure 11) [29]. Compounds were synthesized by the reaction of oxoplatin with the corresponding NSAID in the presence of TBTU and triethylamine in DMF. The cytotoxicity of prodrugs 22-24 was assessed by MTT assay. $\mathrm{IC}_{50}$ values of prodrug 22 were lower than the values of cisplatin on malignant cell lines MCF-7, A549 and HeLa, while being less toxic than cisplatin on the normal cell line MRC-5 (Table 11). Complex 24 showed comparable results to cisplatin toxicity on MCF-7 and A549 cell lines, while being less toxic on the HeLa cell line. The most potent prodrug, 22, was 14-fold more active than cisplatin. Cellular accumulation in MCF-7 cells after 3 hours of incubation was assessed by ICP-MS assay, which indicated that the trend in antiproliferative activity correlated with the cellular uptake level, with prodrug 22 showing the highest level of platinum content.

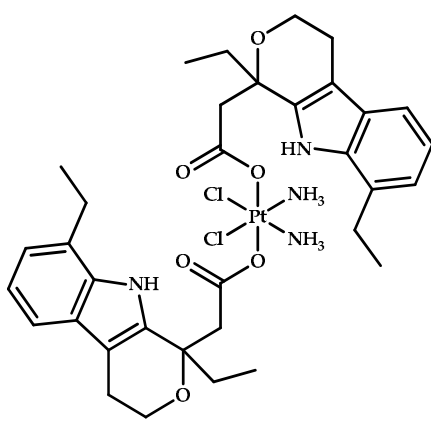

22

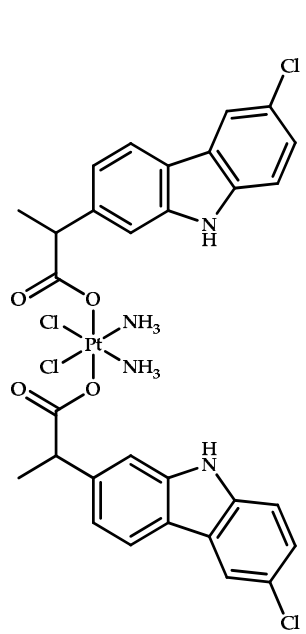

23

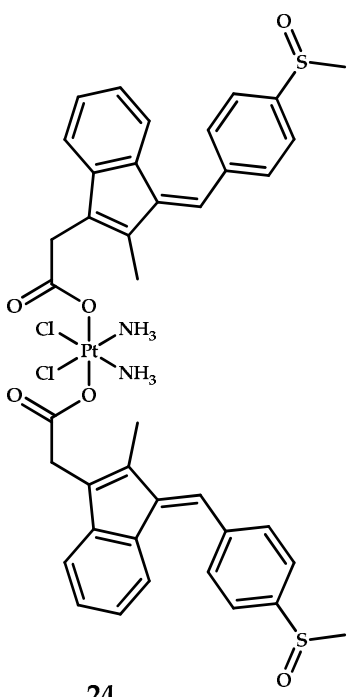

24

Figure 11. Platinum(IV) prodrugs with etodolac 22, carprofen 23 and sulindac 24 moieties as axial ligands.

Table 11. Antiproliferative activity of cisplatin and prodrugs 22-24 on MCF-7 (breast cancer), A549 (lung carcinoma), HeLa (cervical cancer), and MCR-5 (embryo fibroblast) cell lines. LogP values and cellular uptake in MCF-7 cells are also shown.

\begin{tabular}{ccccccc}
\hline \multirow{2}{*}{ Compound/Cell Line } & \multicolumn{4}{c}{ IC $_{\mathbf{5 0},} \boldsymbol{\mu M}$} & \multirow{2}{*}{ LogP } & \multirow{2}{*}{ Cellular Uptake, ng Pt/10 $\mathbf{6}^{\mathbf{C}}$ Cells } \\
\cline { 2 - 5 } & MCF-7 & A549 & HeLa & MRC-5 & & 200 \\
Cisplatin & $13.31 \pm 2.90$ & $11.29 \pm 0.21$ & $9.82 \pm 0.52$ & $4.92 \pm 0.13$ & -4.86 & 7000 \\
$\mathbf{2 2}$ & $0.95 \pm 0.42$ & $2.78 \pm 0.28$ & $3.59 \pm 0.17$ & $6.24 \pm 1.10$ & 2.56 & 2100 \\
$\mathbf{2 3}$ & $2.68 \pm 1.09$ & $3.87 \pm 1.03$ & $2.99 \pm 0.07$ & $7.06 \pm 0.91$ & 3.92 & 1900 \\
$\mathbf{2 4}$ & $9.02 \pm 2.83$ & $10.64 \pm 0.06$ & $42.33 \pm 7.52$ & $14.04 \pm 3.04$ & -0.42 & \\
\hline
\end{tabular}

Lipophilicity is considered the crucial factor for drug activity, so the $\log \mathrm{P}$ values were obtained for cisplatin and the cisplatin-based prodrugs 22-24. The established optimum $\log \mathrm{P}$ values for maximum drug bioavailability is reported to be in the range of $0-3[44,45]$. Among all three prodrugs (22-24), only one $\log P$ value was in the optimum range (prodrug 22) (Table 11). Cisplatin and prodrug 24 showed lipophilicities lower than optimum, while prodrug 23 had a $\log P$ value higher than optimum. Thus, the obtained lipophilicity values correlate with trend in cytotoxicity and cellular accumulation.

Western blot analysis conducted on MCF-7 cells incubated with prodrug 22 showed the ability of the compound to downregulate the expression of COX-2 and MDM-2 enzymes in MCF-7 cells while inducing the expression of the pro-apoptotic genes Bax and p53. 
Wound healing and invasion assays were conducted to assess whether prodrug 22 is able to suppress the metastasis and invasion of tumor cells. The migration rate of MCF7 cells incubated with complex 22 was significantly lower than the rate of control and cisplatin-treated cells $(18.1 \%, 47.7 \%$, and 39.9\%, respectively) [29].

The In vivo study of prodrug 22 on xenograft mice bearing MCF-7 tumors revealed the low systemic toxicity of prodrug 22, and its ability to suppress tumor growth was slightly stronger than cisplatin after 14 days of treatment $\left(457 \mathrm{~mm}^{3}\right.$ and $570 \mathrm{~mm}^{3}$, respectively). It is notable that the suppression of tumor growth in the case of prodrug 22 was accompanied with slightly reduced platinum content in the heart, liver, and lung than in the case of cisplatin, as assessed by ICP-MS analysis of harvested organs. The body weight of mice treated with prodrug 22 remained almost unchanged, while treatment with cisplatin led to a decrease in body weight by $2 \mathrm{~g}$ on average, from 19 to $17 \mathrm{~g}$. Thus, despite suppressing tumor growth to a higher extent than cisplatin, prodrug 22 also induced significantly fewer toxic effects [29].

\section{Triple Action Asymmetric Pt(IV) Prodrugs with NSAIDs and Other Biologically Active Axial Ligands}

The prodrug approach allows us to combine several bioactive moieties in a single molecule, which opens the way for the fine tuning of the coordination compound's antitumor activity. The possibility of the step-by-step conjugation of axial ligands to obtain unsymmetrical $\mathrm{Pt}(\mathrm{IV})$ prodrugs opens the way for the preparation of triple action $\mathrm{Pt}(\mathrm{IV})$ prodrugs. Several papers demonstrate that upon release, all bioactive moieties exhibit their properties, leading to the increased antitumor efficiency of platinum-based drugs (Table 12) [46-48].

Table 12. Triple action platinum(IV) prodrugs with NSAIDs and another bioactive ligands in the axial position.

\begin{tabular}{|c|c|c|c|c|}
\hline Compound & COX-Inhibitor & Second Axial Ligand & $\begin{array}{c}\text { Confirmation of Second Bioactive } \\
\text { Ligand Action }\end{array}$ & Reference \\
\hline 26 & Indomethacin & $\begin{array}{l}\text { Biotin (biotin receptors } \\
\text { targeting) }\end{array}$ & $\begin{array}{l}\text { Selectivity to tumor cells is attributed } \\
\text { to increased amount of biotin } \\
\text { receptors SMVT }\end{array}$ & [49] \\
\hline 27 & Aspirin & Dichloroacetate (DCA) & MMP depolarization & \\
\hline 28 & Ibuprofen & (PDK inhibitor) & MMP depolarization & \\
\hline 29 & Aspirin & Phenylbutyrate (PhB) & HDAC inhibition & \\
\hline 30 & Ibuprofen & (HDAC inhibitor) & HDAC inhibition & [50] \\
\hline 31 & Ibuprofen & Valproate (Val) (HDAC & HDAC inhibition & \\
\hline 32 & Aspirin & inhibitor) & HDAC inhibition & \\
\hline 33 & Aspirin & $\begin{array}{l}\text { Estramustine (tubulin } \\
\text { inhibitor) }\end{array}$ & $\begin{array}{c}\text { Increase in cell population arrested in } \\
\mathrm{G} 2 / \mathrm{M} \text { phase compared to cisplatin. } \\
\text { Free estramustine is known to arrest } \\
\text { the cell cycle in } \mathrm{G} 2 / \mathrm{M}\end{array}$ & [51] \\
\hline
\end{tabular}

\subsection{Indometacin/Biotin}

Cisplatin-based prodrug 26, with non-steroidal anti-inflammatory drug indomethacin, and biotin (vitamin $\mathrm{H}$ ) with an increased affinity for tumor cells as a second axial ligand was designed by Hu et al. [49] (Figure 12). Prodrug 26 was synthesized by the reaction of oxoplatin with TBTU-activated indomethacin, followed by the reaction of the resulting complex 26a with TBTU-activated biotin. Cisplatin-based prodrug 25, with one indomethacin axial ligand and chlorine as the second axial ligand, was synthesized and used as a control.

The cytotoxicity of both complexes, 25 and 26, and cisplatin as a control, were evaluated by MTT assay on HCT-116 (colorectal cancer), HepG-2 (hepatocellular carcinoma), PC-3 (prostate carcinoma), LO-2 (normal liver), EA.hy926 (umbilical vein endothelial cell), SGC7901 (gastric cancer), and SGC7901/CDDP (cisplatin-resistant gastric cancer) cell lines (Table 13). Complex 25 without the biotin moiety was the most toxic towards nearly all cell lines, while complex 26 showed lesser activity than cisplatin on nearly all malignant 
cells. However, prodrug $\mathbf{2 6}$ showed maximum toxicity towards the cisplatin-resistant cell line SGC7901/CDDP out of the three prodrugs tested, showing 9-fold higher toxicity than cisplatin. It is also worth noting that prodrug $\mathbf{2 6}$ was less toxic towards normal cells (LO-2 and EA.hy926; 17- and 5-fold less, respectively), than cisplatin, indicating the significant selectivity of prodrug $\mathbf{2 6}$ for cancer cells [49].
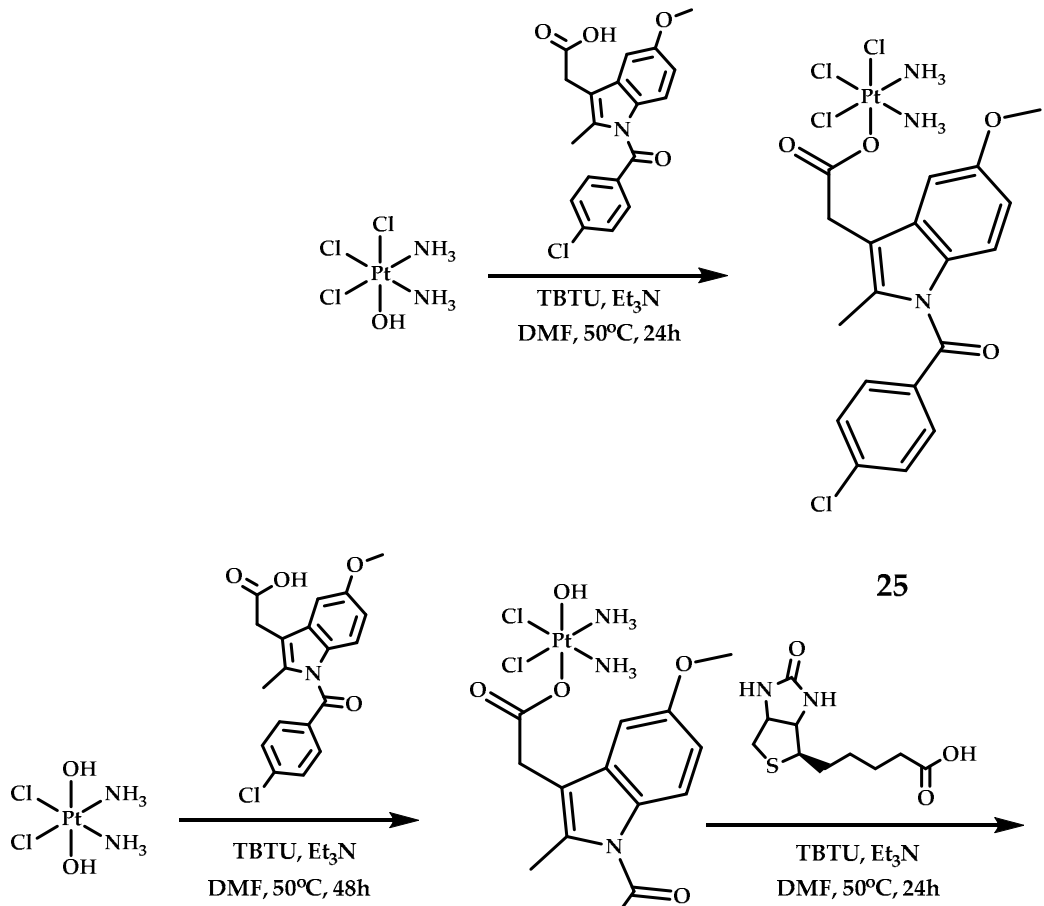

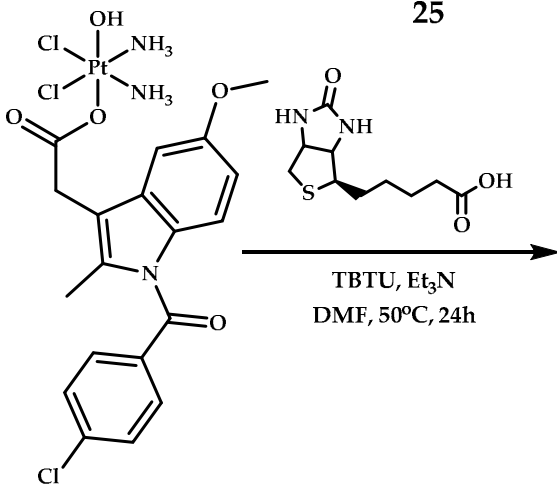

$26 a$

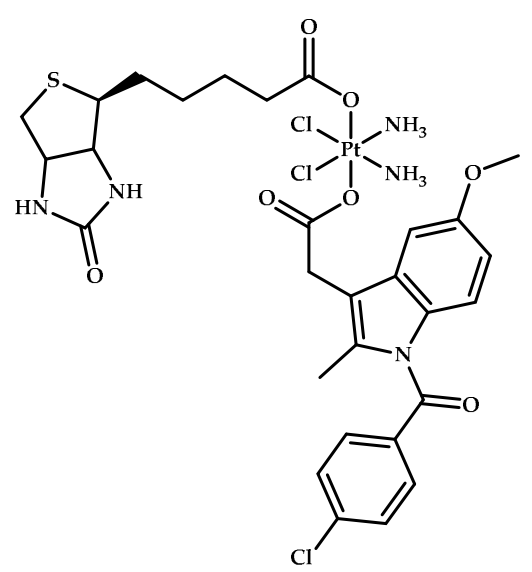

26

Figure 12. Cisplatin-based platinum(IV) prodrugs 25, 26a, and 26 with indomethacin and biotin as axial ligands.

Table 13. Antiproliferative activity of cisplatin and platinum(IV) prodrugs 25 and 26 on HCT-116 (colorectal cancer), HepG-2 (hepatocellular carcinoma), PC-3 (prostate carcinoma), LO-2 (normal liver), EA.hy926 (umbilical vein endothelial cell), SGC7901 (gastric cancer), and SGC7901/CDDP (cisplatin-resistant gastric cancer) cell lines. Rf: ratio of IC 50 value for a cisplatin-resistant cell line and $\mathrm{IC}_{50}$ value for a cisplatin-sensitive line (IC 50 SGC7901/CDDP / IC 50 SGC7901).

\begin{tabular}{|c|c|c|c|c|c|c|c|c|}
\hline \multirow{2}{*}{ Compound/Cell Line } & \multicolumn{8}{|c|}{$\mathrm{IC}_{50}, \mu \mathrm{M}$} \\
\hline & HCT-116 & HepG-2 & PC-3 & LO-2 & EA.hy926 & SGC7901 & SGC7901/CDDP & Rf \\
\hline Cisplatin & $7.78 \pm 0.63$ & $3.96 \pm 0.28$ & $0.95 \pm 0.07$ & $3.54 \pm 0.26$ & $7.42 \pm 0.36$ & $1.11 \pm 0.09$ & $8.18 \pm 0.73$ & 7.37 \\
\hline 25 & $4.94 \pm 0.37$ & $2.35 \pm 0.18$ & $0.81 \pm 0.07$ & $4.79 \pm 0.32$ & $9.61 \pm 0.23$ & $1.36 \pm 0.09$ & $4.50 \pm 0.41$ & 3.31 \\
\hline 26 & $19.27 \pm 1.4$ & $9.67 \pm 0.84$ & $7.24 \pm 0.26$ & $59.64 \pm 2.32$ & $41.73 \pm 2.1$ & $3.27 \pm 0.26$ & $0.91 \pm 0.06$ & 0.29 \\
\hline
\end{tabular}

The intracellular accumulation/distribution of prodrugs 25 and 26 was evaluated using ICP-MS assay on PC-3, SGC7901, and SGC7901/CDDP cell lines after 12 hours of incubation (Table 14). A high level of platinum accumulation was observed for prodrug 26 in various cancer cells, surpassing the accumulation of both prodrug 25 and cisplatin. At the same time, platinum uptake level in a normal cell line (LO-2) for complex 26 was nearly two-fold lower than for cancer cells, and was similar to complex 25 . This is probably due to the higher level of biotin receptors in PC-3, SGC7901, and SGC7901/CDDP cells than in normal cells (LO-2) [49]. 
Table 14. Cellular uptake in PC-3 (prostate carcinoma), SGC7901 (gastric cancer), SGC7901/CDDP (cisplatin-resistant gastric cancer), and LO-2 (normal liver) cell lines preincubated with prodrugs 25, 26, and cisplatin after 12 hours of incubation (ng/106 cells).

\begin{tabular}{ccccc}
\hline \multirow{2}{*}{ Compound/Cell Line } & \multicolumn{4}{c}{ Cellular Uptake, $\mathbf{n g} / \mathbf{1 0}^{\mathbf{6}}$ Cells } \\
\cline { 2 - 5 } & PC-3 & SGC7901 & SGC7901/CDDP & LO-2 \\
\hline Cisplatin & 133 & 120 & 28 & 141 \\
$\mathbf{2 5}$ & 276 & 451 & 269 & 372 \\
$\mathbf{2 6}$ & 839 & 790 & 757 & 403 \\
\hline
\end{tabular}

Both cisplatin and prodrug 25 arrested the cell cycle mainly in the G0/G1 phase, while for prodrug 26, an increase in the cell population at the G2/M phase was observed after 72 hours of incubation in PC-3 cells. Apoptosis studies on PC-3 cells after 72 hours of incubation showed that prodrug 26 induced $30.68 \%$ and $25.01 \%$ of early and late apoptosis, respectively. Contrary to complex $\mathbf{2 6}$, apoptosis induced by prodrug $\mathbf{2 5}$ was slightly lower ( $25.4 \%$ and $23.35 \%$ of early and late apoptotic cells, respectively). Also, the expression of pro- and anti-apoptotic proteins of the Bcl-2 family in PC-3 cells was studied to evaluate their role in the mechanism of cell death induced by the Pt(IV) prodrugs 25 and 26 [52]. Western blot analysis of PC-3 cells after 12 hours of incubation showed a clear increase in the expression of Bax pro-apoptotic proteins for cisplatin and prodrugs 25 and 26, while the level of anti-apoptotic protein Bcl-2 was downregulated by both prodrugs $\mathbf{2 5}$ and $\mathbf{2 6}$ and cisplatin, with $\mathbf{2 6}$ showing the greatest reduction in Bcl-2 protein level.

As indomethacin is a potent non-selective COX inhibitor [53], the ability of $\mathrm{Pt}(\mathrm{IV})$ prodrugs 25 and 26 to inhibit COX-1 and COX-2 was studied in vitro via enzyme immunoassay. Both prodrugs 25 and 26 showed concentration-dependent inhibition of both COX-1 and COX-2. Interestingly, while free indomethacin showed a stronger inhibition of COX-1 than prodrugs $\mathbf{2 5}$ and 26, both complexes surpassed free NSAID in terms of COX-2 inhibition. This fact is attributed to the esters of indomethacin, which have been reported to show COX-2 selectivity [54]. The authors assumed that indomethacin was not released from the prodrugs and that the $\mathrm{Pt}(\mathrm{IV})$ prodrugs $\mathbf{2 5}$ and $\mathbf{2 6}$ were able to inhibit COX-1 and COX-2 despite indomethacin not being released from the complex.

\subsection{Ibuprofen, Aspirin/PDK, PhB, Val, and HDAC Inhibitors}

In recent work published by Petruzella et al. [50], eight triple action $\mathrm{Pt}(\mathrm{IV})$ prodrugs bearing ligands with different bioactive properties were obtained. Aspirin and ibuprofen were selected as COX-2 inhibitors, dichloroacetate was chosen as a potent pyruvate dehydrogenase kinase (PDK) inhibitor, and phenylbutyrate (PhB) or valproate (Val) as histone deacetylase (HDAC) inhibitors. PDK inhibits the pyruvate dehydrogenase complex (PDHC), which plays a key role in cellular respiration [55]. In tumor cells, PDHC is inhibited, and thus cellular metabolism is shifted from glucose oxidation to glycolysis (Warburg effect) [56]. The inhibition of PDK reverses that process, leading to cell death. Inhibition of HDAC was shown to lead to chromatin de-condensation, thus making cellular DNA more sensitive to platination [57]. The synergy between HDAC inhibition and anti PD-L1 immune checkpoint blockade has been reported in several ovarian cancers [58].

Synthesis of the prodrugs 27-32 (Figure 13) was performed by two consecutive carboxylations of oxoplatin by the corresponding acid anhydride.

Stability of the prodrugs 27-32 in phosphate buffer was monitored by HPLC. Prodrugs 28 and 31 were stable throughout the experiment, but after the first day, prodrugs 29, 30 and 32 showed 10\%, 25\% and 20\% degradation, respectively. Prodrug 27 was found to be the least stable, with about half the complex degraded in the first day and the rest of the compound in the following days. The general trend was that aspirin prodrugs were less stable than ibuprofen ones [50]. 
<smiles>CC(=O)Oc1ccccc1C(=O)O[I+](N)(N)(Cl)(Cl)OC(=O)C(Cl)Cl</smiles>

27<smiles></smiles>

28

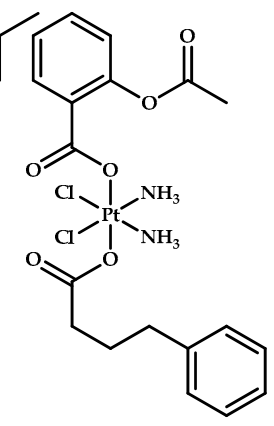

29

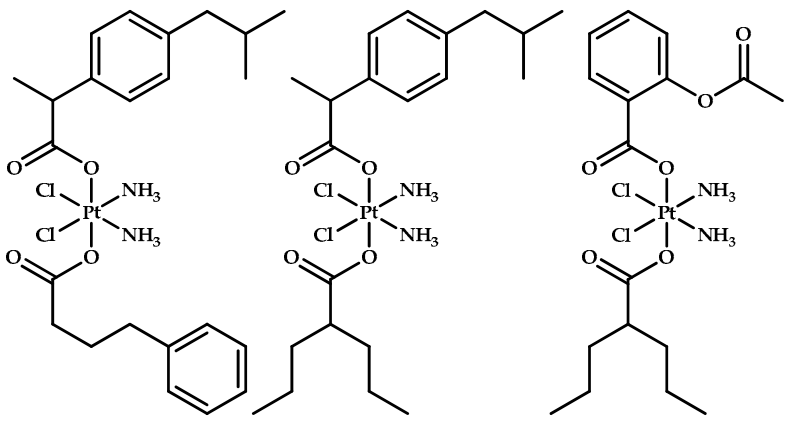

30

31

32

Figure 13. Cisplatin-based triple action prodrugs 27-32 with ibuprofen $(\mathbf{2 8}, \mathbf{3 0}, \mathbf{3 1})$, aspirin $(\mathbf{2 7}, \mathbf{2 9}, \mathbf{3 2})$, dichloroacetate $(27$, $28)$, phenylbutyrate $(29,30)$ and valproate $(31,32)$ moieties in axial positions.

The cytotoxicity of the prodrugs was studied on the various cell lines; $\mathrm{IC}_{50}$ values were obtained after 72 hours of incubation. All triple action prodrugs were more toxic than cisplatin, with average $\mathrm{IC}_{50}$ values on BCAP and PSN-1 cells being 51- and 71-fold lower, respectively, than the $\mathrm{IC}_{50}$ values of cisplatin All prodrugs showed nanomolar $\mathrm{IC}_{50}$ values on LoVo and PSN-1 cell lines and submicromolar or nanomolar $\mathrm{IC}_{50}$ values on other cell lines (Table 15) [50].

Table 15. Antiproliferative activity of cisplatin and platinum(IV) prodrugs 27-32 on HCT-15 (human colon carcinoma), BCAP (thyroid cancer), PSN-1 (pancreatic cancer), LoVo (colon cancer), 2008 (ovarian adenocarcinoma), and C13* (cisplatinresistant ovarian adenocarcinoma) cell lines. Resistance factor $(\mathrm{RF})=\mathrm{IC}_{50}\left(\mathrm{C} 13^{*}\right) / \mathrm{IC}_{50}(2008)$.

\begin{tabular}{|c|c|c|c|c|c|c|c|c|}
\hline \multirow{2}{*}{ Class } & \multicolumn{8}{|c|}{$\mathrm{IC}_{50}, \mu \mathrm{M}$} \\
\hline & Compound/Cell Line & HCT-15 & ВСРАР & PSN-1 & LoVo & 2008 & C13* & RF \\
\hline \multirow{3}{*}{ PDKi, COXi } & 27 & $1.03 \pm 0.25$ & $0.06 \pm 0.005$ & $0.06 \pm 0.008$ & $0.755 \pm 0.06$ & $0.61 \pm 0.19$ & $1.66 \pm 0.09$ & 2.7 \\
\hline & 28 & $0.65 \pm 0.17$ & $0.14 \pm 0.04$ & $0.08 \pm 0.01$ & $0.285 \pm 0.02$ & $0.32 \pm 0.09$ & $0.97 \pm 0.22$ & 3 \\
\hline & 29 & $1.86 \pm 0.41$ & $0.06 \pm 0.004$ & $0.09 \pm 0.02$ & $0.055 \pm 0.01$ & $0.29 \pm 0.11$ & $0.43 \pm 0.12$ & 1.5 \\
\hline \multirow{3}{*}{ HDACi, COXi } & 30 & $4.98 \pm 1.25$ & $0.08 \pm 0.01$ & $0.92 \pm 0.2$ & $0.211 \pm 0.08$ & $0.89 \pm 0.19$ & $1.65 \pm 0.11$ & 1.9 \\
\hline & 31 & $3.98 \pm 0.89$ & $0.68 \pm 0.08$ & $0.07 \pm 0.01$ & $0.034 \pm 0.03$ & $1.35 \pm 0.29$ & $1.61 \pm 0.42$ & 1.2 \\
\hline & 32 & $4.51 \pm 0.85$ & $0.01 \pm 0.003$ & $0.13 \pm 0.04$ & $0.97 \pm 0.08$ & $0.69 \pm 0.08$ & $0.77 \pm 0.04$ & 1.1 \\
\hline \multirow{2}{*}{ Reference } & Cisplatin & $15.28 \pm 2.63$ & $7.38 \pm 1.53$ & $18.25 \pm 3.11$ & $9.15 \pm 2.07$ & $2.22 \pm 1.02$ & $22.52 \pm 3.15$ & 10.10 \\
\hline & Oxaliplatin & $1.15 \pm 0.43$ & $4.37 \pm 1.07$ & $8.25 \pm 3.42$ & $1.01 \pm 0.34$ & $1.53 \pm 0.88$ & $3.06 \pm 1.00$ & 2.00 \\
\hline
\end{tabular}

Two-dimensional cellular cultures are simplistic models that cannot imitate complex tumor cells processes, and thus they cannot predict the In vivo activity of a certain drug. On the other hand, 3D cell cultures possess important features of real tumors, such as intercellular interactions, hypoxia gradients, and the ability to model drug penetration and resistance [59]. These properties make cellular spheroids a relatively close model of In vivo tumors [60]. A series of triple action prodrugs (27-32) was tested against PSN-1 spheroids of pancreatic cancer. Cisplatin was used as a control. Prodrugs 31 and $\mathbf{3 2}$ with a valproate moiety showed sub-micromolar toxicities and were more than 50 -fold more active than cisplatin. Other prodrugs in the assay were up to 15-fold more cytotoxic than cisplatin.

The absence of selectivity towards malignant cells is the core problem of platinumbased therapeutics and overcoming this issue is crucial for new anticancer drugs [61]. Thus, triple action compounds were screened on non-cancerous HEK293 cells and their selectivity index as ratio of $\mathrm{IC}_{50}$ (HEK293) to the $\mathrm{IC}_{50}$ values of cell lines that were the most sensitive to the complexes was calculated (Table 16). Prodrug 32, with valproate and aspirin moieties, showed high selectivity against BCPAP cells $(\mathrm{SI}=59)$; prodrug 31 , with valproate and ibuprofen moieties, was moderately selective on LoVo cells (SI =13.8); while the other prodrugs did not show high selectivity towards any of the tumor cells (ranging from 0.1 to 2 ). 
Table 16. Antiproliferative activity of platinum(IV) prodrugs 27-32 on HEK293 (non-cancerous embryotic kidney) cell line. Selectivity index $(\mathrm{SI})=\mathrm{IC}_{50}$ (normal cell line) $/ \mathrm{IC}_{50}$ (tumor cell line).

\begin{tabular}{|c|c|c|c|c|c|}
\hline \multirow[b]{2}{*}{ Class } & \multirow[b]{2}{*}{ Compound/Cell Line } & \multirow[b]{2}{*}{ IC $_{50}, \mu \mathrm{M}$ HEK 293} & \multicolumn{3}{|c|}{ Selectivity Index (SI) } \\
\hline & & & PSN-1 & BCPAP & LoVo \\
\hline \multirow{3}{*}{ PDKi, COXi } & 27 & $0.09 \pm 0.02$ & 1.5 & 1.5 & 0.1 \\
\hline & 28 & $0.07 \pm 0.03$ & 0.9 & 0.5 & 0.2 \\
\hline & 29 & $0.11 \pm 0.01$ & 1.2 & 1.8 & 2 \\
\hline \multirow{3}{*}{ HDACi, COXi } & 30 & $0.13 \pm 0.03$ & 0.1 & 1.6 & 0.6 \\
\hline & 31 & $0.47 \pm 0.08$ & 6.7 & 0.7 & 13.8 \\
\hline & 32 & $0.59 \pm 0.21$ & 4.5 & 59 & 0.6 \\
\hline Reference & Cisplatin & $19.62 \pm 2.33$ & & & \\
\hline
\end{tabular}

Platinum drugs exhibit their cytotoxic action through DNA platination; thus, platinum cellular accumulation and DNA platination are key parameters that define the efficiency of platinum drugs. To investigate whether the increased cytotoxicity of prodrugs 27-32 is due to increased platinum uptake and better cisplatin binding to DNA, cellular uptake and DNA platination were evaluated on PSN-1 cells after 24 hours of incubation with $1 \mu \mathrm{M}$ of each prodrug (27-32) and cisplatin (Table 17). The results indicate that there is no correlation between cellular uptake and cytotoxic activity. The most potent prodrug, 27, showed the lowest level of platinum in PSN-1 cells, while prodrugs with similar $\mathrm{IC}_{50}$ values (28 and 31) showed the highest values of platinum uptake. No correlation between toxicity and nuclear DNA platination was observed either. Prodrug 30 showed the highest platination level; however, it is the least active prodrug in the series [50].

Table 17. Cellular uptake, DNA platination, and the ability of prodrugs 27-32 to inhibit HDAC and COX-2 and cause mitochondria depolarization in PSN-1 (pancreas cancer) cells.

\begin{tabular}{|c|c|c|c|c|c|c|}
\hline Class & Compound & $\begin{array}{c}\text { Cellular } \\
\text { Uptake, ng } \\
\text { Pt/10 } 10^{6} \text { Cells }\end{array}$ & 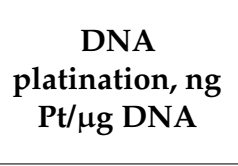 & $\begin{array}{c}\text { HDAC } \\
\text { Inhibition, \% }\end{array}$ & $\begin{array}{c}\text { COX-2 } \\
\text { Inhibition, \% }\end{array}$ & $\begin{array}{c}\text { Cells with } \\
\text { Depleted } \\
\text { Mitochondrial } \\
\text { Potential, \% }\end{array}$ \\
\hline \multirow{3}{*}{ PDKi, COXi } & 27 & 5 & 0.3 & $<1$ & 9 & 15 \\
\hline & 28 & 20 & 1.5 & $<1$ & 9 & 28 \\
\hline & 29 & 13 & 0.8 & 8 & 6.1 & 39 \\
\hline \multirow{4}{*}{ HDACi, COXi } & 30 & 6 & 2.3 & 9 & 7.9 & 29 \\
\hline & 31 & 17 & 0.75 & 7.5 & 11.2 & 32 \\
\hline & 32 & 7.5 & 0.2 & 8 & 4.1 & 25 \\
\hline & Cisplatin & 3 & 1.2 & 1 & 3 & 3 \\
\hline
\end{tabular}

The ability of prodrugs 27-32 to inhibit HDAC was evaluated in PSN-1 cells (Table 16). Prodrugs 29-32 with PhB and Val in the axial positions showed high inhibitory activities towards HDAC; however, no correlation between the inhibition of HDAC and toxicity was observed.

The COX-2 inhibition ability of prodrugs $27-32$ on the PSN-1 cell line was studied as well. Surprisingly, ibuprofen-containing prodrugs 28, 30, and 31 showed high inhibitory activity, contrary to the results in previous reports (Section 2.1) with the ibuprofenplatinum(IV) prodrugs 3 and $\mathbf{5}$. Furthermore, prodrug 31 turned out to be the most potent COX inhibitor in the series (11\% inhibition), while aspirin-containing prodrug 32 was the least active [50].

Dichloroacetate is reported to cause imbalances in redox homeostasis, leading to reactive oxygen species (ROS) production and damage to mitochondria [62]. Thus, the activity of the dichloroacetate moiety in prodrugs $\mathbf{2 7}$ and 28 was assessed by measuring intracellular ROS level and changes in mitochondrial membrane potential. Val-containing prodrugs 31 and 32 caused significant increases in intracellular ROS level in PSN-1 cells despite the absence of a dichloroacetate (DCA) ligand, while PSN-1 cells incubated with 
the DCA-containing prodrugs $\mathbf{2 7}$ and $\mathbf{2 8}$ demonstrated a lower level of ROS in PSN-1 cells (Table 16). An increase in intracellular ROS level leads to hypopolarization of the mitochondrial membrane [63]. Thus, a change in the membrane mitochondrial potential was evaluated in PSN-1 cells incubated with prodrugs 27-32. All triple action prodrugs showed a higher mitochondrial membrane depolarization ability than cisplatin, with prodrugs 29 and 31 causing the highest hypopolarization (25-40\%) (Table 16). Interestingly, complexes 29-32 with no mitochondria-active moieties showed significant mitochondrial depolarization activity as well.

Thus, no simple correlation between a certain toxicity mechanism and the biological activity of triple action prodrugs 27-32 was revealed. More likely, a complex synergistic effect based on specific cellular interactions of each of the components is taking place [50].

\subsection{Aspirin/Estramustine}

A large class of potent anticancer drugs exhibit their antiproliferative action by disrupting mitotic spindle assembly [64]. Paclitaxel and docetaxel act as microtubule-targeting agents (MTAs), inhibiting tubulin activity which leads to the disruption of intracellular transport and inhibition of cell proliferation [65]. A number platinum(IV) prodrugs with MTAs have been already described [66,67]. Recently, Karmakar et al. [51] have reported on a series of platinum(IV) prodrugs with estramustine, an FDA-approved MTA for the palliative treatment of metastatic prostate carcinoma. The designed series consist of unsymmetrical prodrugs with estramustine and various other inhibitors, such as HDAC inhibitors, PDK inhibitors, and COX inhibitors, in axial positions. For the scope of this review, only aspirin-containing $\mathrm{Pt}(\mathrm{IV})$ prodrug 33 is considered (Figure 14).

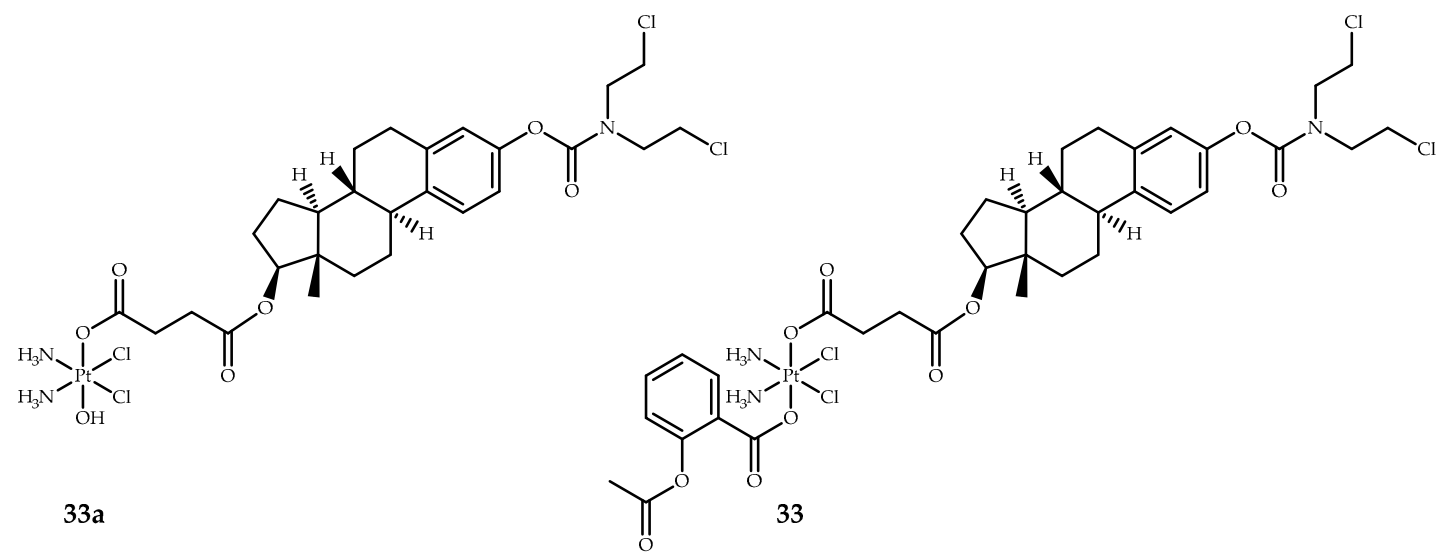<smiles>CC(=O)O[I+](N)(Cl)(Cl)(Cl)OC(=O)CCC(=O)O[C@H]1CC[C@H]2[C@]1(C)CC[C@H]1c3ccc(OC(=O)N(CCCl)CCCl)cc3CC[C@]12C</smiles>

34

Figure 14. Cisplatin-based platinum(IV) prodrugs 33a, 33, and 34 with an estramustine moiety in the axial position. Prodrug 33 contains an aspirin moiety in the axial position. 
Prodrug 33 was synthesized via several steps. First, estramustine was reacted with succinic anhydride to obtain estramustine succinate, which was then activated by Nhydroxysuccinimide (NHS). The estramustine-cisplatin conjugate 33a was obtained by reacting oxoplatin with the NHS-ester of estramustine succinate. Prodrug 33 was synthesized by the carboxylation of the 33a by aspirin anhydride. Prodrug 33 was found to be stable in phosphate buffer with a half-life of several days. The analysis of prodrug 33 reduction in phosphate buffer by 10 equivalents of ascorbic acid determined that half of the complex is reduced in 4.2 hours. [51].

The cytotoxicity of $\mathbf{3 3}$ was assessed by MTT assay, with cisplatin, free estramustine, and prodrug 33a as controls (Table 18). While cisplatin and the free ligand showed $\mathrm{IC}_{50}$ values in the range of 6-26 $\mu \mathrm{M}$, for prodrug $33 \mathrm{a}, \mathrm{IC}_{50}$ values were in the sub-micromolar range $(0.19-0.9 \mu \mathrm{M})$. The triple action drug 33 , however, was found to be much more toxic on all cell lines compared to cisplatin and prodrug 33a, with toxicities ranging from 0.09 to $0.45 \mu \mathrm{M}$. The $\mathrm{IC}_{50}$ values were also determined for the non-cancerous cell line MCR-5 pd30 to assess the selectivity of the prodrug. The selectivity index was determined against LNCaP and DU145 prostate cancer cells. Prodrug 33 showed low toxicity $(2.2 \mu \mathrm{M})$ and high selectivity towards malignant cells. The selectivity index of prodrug 33 was more than 18, while for control compounds (cisplatin and free estramustine), it did not surpass 3 (although for 33a, the SI was close to that of 33 (17.7 and 18.3, respectively)) [51].

Table 18. Antiproliferative activity of prodrugs 33a, 33 and 34 on LNCaP (prostate cancer), DU145 (prostate cancer), MDA-MB-231 (triple negative breast adenocarcinoma), MCF-7 (breast cancer), and HCT-116 (colon cancer) cell lines. MCR-5 pd30 (fetal lung normal cell line) was used as a reference. Selectivity index $(\mathrm{SI})=\mathrm{IC}_{50} \mathrm{MCR}-5 \mathrm{pd} 30 /$ average $\mathrm{IC}_{50}(\mathrm{LNCaP}$ and DU145).

\begin{tabular}{cccccccc}
\hline \multirow{2}{*}{$\begin{array}{c}\text { Compound/ } \\
\text { Cell Line }\end{array}$} & LNCaP & DU145 & $\begin{array}{c}\text { MDA-MB- } \\
\text { 231 }\end{array}$ & MCF-7 & HCT116 & MCR-5 pd30 & SI \\
\cline { 2 - 7 } & $0.09 \pm 0.02$ & $0.15 \pm 0.03$ & $0.18 \pm 0.01$ & $0.45 \pm 0.06$ & $0.32 \pm 0.08$ & $2.2 \pm 0.3$ & 18.3 \\
33 & $0.24 \pm 0.06$ & $0.19 \pm 0.04$ & $0.54 \pm 0.06$ & $0.7 \pm 0.1$ & $0.9 \pm 0.1$ & $3.8 \pm 0.6$ & 17.7 \\
$33 a$ & $0.26 \pm 0.03$ & $0.27 \pm 0.01$ & $0.6 \pm 0.1$ & $0.8 \pm 0.1$ & $1.0 \pm 0.2$ & $3.6 \pm 0.2$ & 13.6 \\
34 & $6 \pm 1$ & $11 \pm 1$ & $5.5 \pm 0.9$ & $12.6 \pm 0.9$ & $26 \pm 2$ & $25 \pm 3$ & 2.9 \\
Estramustine & $2.4 \pm 0.2$ & $21 \pm 3$ & $14.8 \pm 0.9$ & $9 \pm 1$ & $2.4 \pm 0.2$ & $9 \pm 2$ & 2.6 \\
Cisplatin & & & & & & & \\
\hline
\end{tabular}

The intracellular accumulation of prodrug 33 in LNCaP cells was evaluated by ICP-MS assay. Compared to cisplatin, intracellular platinum level for prodrug $\mathbf{3 3}$ was 46 -fold higher after 6 hours of incubation with $10 \mu \mathrm{M}$ of the compound (Table 19).

Table 19. Cellular uptake in LNCaP cells preincubated with $10 \mu \mathrm{M}$ of prodrugs 33,34 and cisplatin for 6 hours and their corresponding $\log P$ values.

\begin{tabular}{ccc}
\hline Compound & Cellular Uptake, $\mathbf{n g} \mathbf{P t} / \mathbf{1 0}^{\mathbf{6}}$ Cells & LogP \\
\hline $\mathbf{3 3}$ & $172 \pm 37$ & $0.18 \pm 0.04$ \\
$\mathbf{3 4}$ & $139 \pm 16$ & $-0.01 \pm 0.08$ \\
Cisplatin & $3.7 \pm 0.8$ & $-2.3 \pm 0.4$ \\
\hline
\end{tabular}

$\log P$ values of cisplatin and 33 were determined by the shake-flask method. When the lipophilicities of other prodrugs in the series had been considered, a clear correlation between lipophilicity and platinum uptake was observed. Based on these results, the authors assumed that the prodrugs were able to enter the cells intact without being reduced in the extracellular medium [51].

The study of the cell cycle arrest caused by prodrug 33 in LNCaP cells was utilized to determine whether both estramustine and cisplatin contribute to the mechanism of action of prodrug 33. Estramustine was found to stop the cell cycle mainly in the G2/M phase due to its antitubulin activity, while cisplatin mainly arrested the cell cycle in the $S$ phase 
(and partly in the G1 phase). For prodrug 33, the cell cycle was arrested mainly in the G1 phase, with a significant share of the $S$ and G2/M phases. Thus, the effect of both bioactive moieties on cell cycle arrest was clearly shown [51].

Autophagy is a process used by cells to degrade damaged or unneeded organelles. NSAIDs, notably aspirin, are capable of inducing autophagy in HCT116 human colon cancer cells [68]. Thus, the ability of prodrug 33 to induce autophagy was investigated by Western blot analysis of the protein extracts from LNCaP cells. Prodrug 33 showed an ability to induce autophagy in LNCaP cells in a concentration-dependent manner, which was seen from the expression levels of p62, which was efficiently degraded by autophagy. On the other hand, the estramustine-cisplatin prodrug 34, with acetyl as the second axial ligand, did not induce any changes in p62 expression.

Thus, a highly potent triple action platinum(IV) prodrug 33 with estramustine and aspirin as axial ligands was obtained. The prodrug 33 was found to be up to 110-fold more cytotoxic than cisplatin and up to 80-fold more cytotoxic than estramustine, suggesting a synergetic effect. At the same time, the prodrug showed high selectivity toward prostate cancer, as it was 18-fold less toxic on MRC-5 pd30 normal cells than on LNCaP and DU145 on average. This selectivity was not observed for either estramustine or cisplatin. A study on the mechanism of action of prodrug 33 determined that it acts as a multiple-action prodrug, with all three ligands affecting multiple targets in cancer cells: both cisplatin and estramustine moieties act as antiproliferative agents, while aspirin acts as an autophagyinducing agent [51].

\section{Conclusions}

Platinum(IV) prodrugs are one of the most promising classes of novel platinum anticancer agents. Octahedral $\mathrm{Pt}(\mathrm{IV})$ complexes are considered to be kinetically inert, while the axial position can be easily modified. Thus, $\mathrm{Pt}(\mathrm{IV})$ prodrugs can be finely tuned, which facilitates the development of antitumor agents with the desired mode of action. In this review, platinum(IV) prodrugs with NSAIDs in the axial position are considered.

The design of platinum(IV) prodrugs with FDA-approved agents in the axial position is a promising approach due to the well-known pharmacological profile and biocompatibility of anti-inflammatory agents. The conjugation of hydrophilic cisplatin with lipophilic NSAIDs results in a high-lipophilic Pt(IV) prodrug capable of effective cellular penetration and ideally, of slow release of the NSAID and the cytotoxic agent intracellularly. A significant increase in intracellular penetration of $\mathrm{Pt}(\mathrm{IV})$ prodrugs compared to the initial $\mathrm{Pt}(\mathrm{II})$ drugs expectedly leads to impressive increases in antiproliferative activity; most of the prodrugs considered in this review demonstrated $\mathrm{IC}_{50}$ values more than 10 -fold lower than cisplatin, with prodrugs 3, 21, and 27-32 being from 180- to 300-fold more potent than cisplatin. LogP values obtained for several prodrugs demonstrate a clear correlation between intracellular accumulation, lipophilicity, and antiproliferative activity; thus, lipophilicity seems to be a key factor that determines the efficiency of $\mathrm{Pt}(\mathrm{IV})$ prodrugs. The trend between lipophilicity and antiproliferative activity, as demonstrated by Ravera et al. for prodrugs 8 and 9, as well as by Song et al. for prodrugs 22-24 and by Karmakar et al. for prodrug 33, support this assumption.

COX inhibition activity has little to no influence on cytotoxicity; the extremely potent prodrug 3 shows no inhibition activity on either COX isoform, and no correlation between COX expression and cytotoxicity is observed for prodrugs 8 and 9 . However, several $\mathrm{Pt}(\mathrm{IV})$ prodrugs considered in this review, such as 1, 2, 21 and 31, act as potent antiinflammatory agents and can probably reduce the inflammation-induced side effects of platinum chemotherapy; i.e., act as true double-acting drugs.

The step-by-step carboxylation of oxoplatin with different bioactive moieties opens the way for the design of multi-action platinum (IV) prodrugs. Several triple action $\mathrm{Pt}(\mathrm{IV})$ prodrugs with NSAIDs and other bioactive moieties in the axial position are considered in this review. Biochemical assays for prodrugs 26-33 confirmed that each prodrug acts as a triple action compound, possessing biological properties of each of its moieties. In addition, 
the resulting antiproliferative activity of such prodrugs was up to 300-fold more than the antiproliferative activity of cisplatin. Contrary to dual action prodrugs with NSAIDs 1-24, no simple correlation between cytotoxicity and one single parameter was observed for triple action prodrugs 27-32. More likely, a complex synergetic effect of all moieties acting simultaneously is taking place. The design of triple-action $\mathrm{Pt}(\mathrm{IV})$ prodrugs is a new, promising approach which opens up new possibilities for the use of $\mathrm{Pt}(\mathrm{IV})$ prodrugs as chemotherapeutic agents; the lack of data on the therapeutic efficacy of such derivatives In vivo is disappointing.

The results of the In vivo antitumor efficiency of $\mathrm{Pt}(\mathrm{IV})$ prodrugs with NSAIDs as axial ligands published to date (namely 17, 21 and 22) do not allow us to derive exact conclusions. Prodrugs 17 and 22 showed tumor growth inhibition values close to cisplatin on cisplatin-sensitive CT-26 and MCF-7 tumor models, respectively, while prodrug 21 was 10-fold more active In vivo than cisplatin in a cisplatin-resistant MDA-MB-231 tumor model. However, a common trend was observed for all three prodrugs (17, 21 and 22) tested In vivo; the body weight of mice treated with the prodrugs decreased little to none, while the conventional platinum(II) drugs cisplatin and oxaliplatin caused significant body weight loss. Thus, although the general therapeutic efficiency of NSAID-containing platinum(IV) prodrugs is still unclear, it is undoubtable that platinum(IV) prodrugs reduce the side effects and general toxicity of platinum chemotherapy.

Funding: This research was funded by the Ministry of Education and Science of the Russian Federation, implemented by a governmental decree dated 16 March 2013, no. 211, The Russian Science Foundation, grant number 19-74-10059.

Institutional Review Board Statement: Not applicable.

Informed Consent Statement: Not applicable.

Data Availability Statement: Not applicable.

Acknowledgments: We acknowledge the financial support from the Ministry of Education and Science of the Russian Federation in the framework of the Increase Competitiveness Program of NUST "MISIS", implemented by a governmental decree dated 16 March 2013, no. 211 (Introduction and Conclusions). The Russian Science Foundation also provided support via grant no. 19-74-10059.

Conflicts of Interest: The authors declare no conflict of interest.

$\begin{array}{ll}\text { Abbreviations } \\ \text { NSAID } & \text { Non-steroidal anti-inflammatory drug } \\ \text { FDA } & \text { Food and Drug Administration } \\ \text { CML } & \text { Chronic myelogenous leukemia } \\ \text { COX } & \text { Cyclooxygenase } \\ \text { EMT } & \text { Epithelial-mesenchymal transition } \\ \text { MMP } & \text { Matrix metalloproteinase } \\ \text { IC50 } & \text { Half-maximal inhibitory concentrations } \\ 5^{\prime} \text {-GMP } & 2^{\prime} \text {-deoxyguanosine 5'-monophosphate sodium salt hydrate } \\ \text { CDDP } & \text { cis-Diaminedichloroplatinum } \\ \text { TNF- } \alpha & \text { Tumor necrosis factor- } \alpha \\ \text { NMR } & \text { Nuclear magnetic resonance } \\ \text { MTT } & \text { 3-(4,5-dimethylthiazol-2-yl)-2,5-diphenyltetrazolium bromide } \\ \text { CV } & \text { Cyclic voltammetry } \\ \text { RP-HPLC } & \text { Reverse phase-high performance liquid chromatography } \\ \text { AR } & \text { Accumulation ratio } \\ \text { RT-Qpcr } & \text { Quantitative reverse transcription polymerase chain reaction } \\ \text { NHS } & \text { N-hydroxysuccinimide } \\ \text { SI } & \text { Selectivity index }\end{array}$




$\begin{array}{ll}\text { TBTU } & \text { 2-(1H-Benzotriazole-1-yl)-1,1,3,3-tetramethylaminium tetrafluoroborate } \\ \text { DMF } & \text { N,N-Dimethylformamide } \\ \text { ICP-MS } & \text { Inductively coupled plasma mass spectrometry } \\ \text { ESI-MS } & \text { Electrospray ionization mass spectrometry } \\ \text { PDK } & \text { Pyruvate dehydrogenase kinase } \\ \text { PhB } & \text { Phenybutyrate } \\ \text { Val } & \text { Valproate } \\ \text { HDAC } & \text { Histone deacetylase } \\ \text { PDHC } & \text { Pyruvate dehydrogenase complex } \\ \text { HPLC } & \text { High performance liquid chromatography } \\ \text { ROS } & \text { Reactive oxygen species } \\ \text { DCA } & \text { Dichloroacetate } \\ \text { MTA } & \text { Microtubule targeting agent }\end{array}$

\section{References}

1. Wheate, N.J.; Walker, S.; Craig, G.E.; Oun, R. The status of platinum anticancer drugs in the clinic and in clinical trials. Dalt. Trans. 2010, 39, 8113-8127. [CrossRef] [PubMed]

2. O'Dwyer, P.J.; Stevenson, J.P.; Johnson, S.W. Clinical pharmacokinetics and administration of established platinum drugs. Drugs 2000, 59, 19-27. [CrossRef] [PubMed]

3. Zhou, Z.; Jiang, H.; Xia, J.; Zhang, J. Comparison of the therapeutic effects of lobaplatin and carboplatin on retinoblastoma in vitro and In vivo. Int. J. Oncol. 2020, 57, 697-706. [CrossRef] [PubMed]

4. $\quad$ Lee, K.H.; Hyun, M.S.; Kim, H.-K.; Jin, H.M.; Yang, J.; Song, H.S.; Do, Y.R.; Ryoo, H.M.; Chung, J.S.; Zang, D.Y.; et al. Randomized, Multicenter, Phase III Trial of Heptaplatin 1-hour Infusion and 5-Fluorouracil Combination Chemotherapy Comparing with Cisplatin and 5-Fluorouracil Combination Chemotherapy in Patients with Advanced Gastric Cancer. Cancer Res. Treat. 2009, 41, 12. [CrossRef]

5. Cepeda, V.; Fuertes, M.; Castilla, J.; Alonso, C.; Quevedo, C.; Perez, J. Biochemical Mechanisms of Cisplatin Cytotoxicity Anticancer. Agents Med. Chem. 2008, 7, 3-18. [CrossRef] [PubMed]

6. Jamieson, E.R.; Lippard, S.J. Structure, Recognition, and Processing of Cisplatin - DNA Adducts. Chem. Rev. 1999, 99, 2467-2498. [CrossRef]

7. Boussios, S.; Pentheroudakis, G.; Katsanos, K.; Pavlidis, N. Systemic treatment-induced gastrointestinal toxicity: Incidence, clinical presentation and management. Ann. Gastroenterol. 2012, 25, 106-118.

8. Grothey, A. Oxaliplatin-safety profile: Neurotoxicity. Semin. Oncol. 2003, 30, 5-13. [CrossRef]

9. Dasari, S.; Bernard Tchounwou, P. Cisplatin in cancer therapy: Molecular mechanisms of action. Eur. J. Pharmacol. 2014, 740, 364-378. [CrossRef] [PubMed]

10. Johnstone, T.C.; Suntharalingam, K.; Lippard, S.J. The Next Generation of Platinum Drugs: Targeted Pt(II) Agents, Nanoparticle Delivery, and Pt(IV) Prodrugs. Chem. Rev. 2016, 116, 3436-3486. [CrossRef]

11. Hall, M.D.; Mellor, H.R.; Callaghan, R.; Hambley, T.W. Basis for design and development of platinum(IV) anticancer complexes. J. Med. Chem. 2007, 50, 3403-3411. [CrossRef] [PubMed]

12. Choy, H.; Park, C.; Yao, M. Current status and future prospects for satraplatin, an oral platinum analogue. Clin. Cancer Res. 2008, 14, 1633-1638. [CrossRef] [PubMed]

13. Tabas, I.; Glass, C.K. Anti-Inflammatory Therapy in Chronic Disease: Challenges and Opportunities. Science 2013, 339, 166-173. [CrossRef] [PubMed]

14. Ricciotti, E.; Fitzgerald, G.A. Prostaglandins and inflammation. Arterioscler. Thromb. Vasc. Biol. 2011, 31, 986-1000. [CrossRef]

15. Harris, R.E.; Casto, B.C.; Harris, Z.M. Cyclooxygenase-2 and the inflammogenesis of breast cancer. World J. Clin. Oncol. 2014, 5 , 677-692. [CrossRef] [PubMed]

16. Lamouille, S.; Xu, J.; Derynck, R. Molecular mechanisms of epithelial-mesenchymal transition. Nat. Rev. Mol. Cell Biol. 2014, 15, 178-196. [CrossRef]

17. Hanahan, D.; Weinberg, R.A. Hallmarks of cancer: The next generation. Cell 2011, 144, 646-674. [CrossRef]

18. Tsatsanis, C.; Androulidaki, A.; Venihaki, M.; Margioris, A.N. Signalling networks regulating cyclooxygenase-2. Int. J. Biochem. Cell Biol. 2006, 38, 1654-1661. [CrossRef]

19. Zhang, Z.; Chen, F.; Shang, L. Advances in antitumor effects of NSAIDs. Cancer Manag. Res. 2018, 10, 4631-4640. [CrossRef]

20. Pathak, R.K.; Marrache, S.; Choi, J.H.; Berding, T.B.; Dhar, S. The prodrug platin-A: Simultaneous release of cisplatin and aspirin. Angew. Chemie - Int. Ed. 2014, 53, 1963-1967. [CrossRef]

21. Neumann, W.; Crews, B.C.; Marnett, L.J.; Hey-Hawkins, E. Conjugates of cisplatin and cyclooxygenase inhibitors as potent antitumor agents overcoming cisplatin resistance. ChemMedChem 2014, 9, 1150-1153. [CrossRef]

22. Neumann, W.; Crews, B.C.; Sárosi, M.B.; Daniel, C.M.; Ghebreselasie, K.; Scholz, M.S.; Marnett, L.J.; Hey-Hawkins, E. Conjugation of cisplatin analogues and cyclooxygenase inhibitors to overcome cisplatin resistance. ChemMedChem 2015, 10, 183-192. [CrossRef] [PubMed] 
23. Curci, A.; Denora, N.; Iacobazzi, R.M.; Ditaranto, N.; Hoeschele, J.D.; Margiotta, N.; Natile, G. Synthesis, characterization, and in vitro cytotoxicity of a Kiteplatin-Ibuprofen Pt(IV) prodrug. Inorganica Chim. Acta 2018, 472, 221-228. [CrossRef]

24. Tan, J.; Li, C.; Wang, Q.; Li, S.; Chen, S.; Zhang, J.; Wang, P.C.; Ren, L.; Liang, X.J. A Carrier-Free Nanostructure Based on Platinum(IV) Prodrug Enhances Cellular Uptake and Cytotoxicity. Mol. Pharm. 2018, 15, 1724-1728. [CrossRef]

25. Ravera, M.; Zanellato, I.; Gabano, E.; Perin, E.; Rangone, B.; Coppola, M.; Osella, D. Antiproliferative activity of Pt(IV) conjugates containing the non-steroidal anti-inflammatory drugs (NSAIDs) Ketoprofen and Naproxen. Int. J. Mol. Sci. 2019, $20,3074$. [CrossRef]

26. Tolan, D.A.; Abdel-Monem, Y.K.; El-Nagar, M.A. Anti-tumor platinum (IV) complexes bearing the anti-inflammatory drug naproxen in the axial position. Appl. Organomet. Chem. 2019, 33, 1-12. [CrossRef]

27. Chen, Y.; Wang, Q.; Li, Z.; Liu, Z.; Zhao, Y.; Zhang, J.; Liu, M.; Wang, Z.; Li, D.; Han, J. Naproxen platinum(iv) hybrids inhibiting cycloxygenases and matrix metalloproteinases and causing DNA damage: Synthesis and biological evaluation as antitumor agents: In vitro and In vivo. Dalton Trans. 2020, 49, 5192-5204. [CrossRef]

28. Jin, S.; Muhammad, N.; Sun, Y.; Tan, Y.; Yuan, H.; Song, D.; Guo, Z.; Wang, X. Multispecific Platinum(IV) Complex Deters Breast Cancer via Interposing Inflammation and Immunosuppression as an Inhibitor of COX-2 and PD-L1. Angew. Chem. Int. Ed. 2020, 59, 23313-23321. [CrossRef]

29. Song, X.Q.; Ma, Z.Y.; Wu, Y.G.; Dai, M.L.; Wang, D.B.; Xu, J.Y.; Liu, Y. New NSAID-Pt(IV) prodrugs to suppress metastasis and invasion of tumor cells and enhance anti-tumor effect in vitro and In vivo. Eur. J. Med. Chem. 2019, 167, 377-387. [CrossRef] [PubMed]

30. Tosco, P.; Lazzarato, L. Mechanistic insights into cyclooxygenase irreversible inactivation by aspirin. ChemMedChem 2009, 4, 939-945. [CrossRef] [PubMed]

31. Mukherjea, D.; Rybak, L.P.; Sheehan, K.E.; Kaur, T.; Ramkumar, V.; Jajoo, S.; Sheth, S. The design and screening of drugs to prevent acquired sensorineural hearing loss. Expert Opin. Drug Discov. 2011, 6, 491-505. [CrossRef]

32. Trask, C.; Silverstone, A.; Ash, C.M.; Earl, H.; Irwin, C.; Bakker, A.; Tobias, J.S.; Souhami, R.L. A randomized trial of carboplatin versus iproplatin in untreated advanced ovarian cancer. J. Clin. Oncol. 1991, 9, 1131-1137. [CrossRef] [PubMed]

33. Schilder, R.J.; LaCreta, F.P.; Perez, R.P.; Johnson, S.W.; Brennan, J.M.; Rogatko, A.; Nash, S.; McAleer, C.; Hamilton, T.C.; Roby, D.; et al. Phase I and Pharmacokinetic Study of Ormaplatin (Tetraplatin, NSC 363812) Administered on a Day 1 and Day 8 Schedule. Cancer Res. 1994, 54, 709-717.

34. Choi, S.; Filotto, C.; Bisanzo, M.; Delaney, S.; Lagasee, D.; Whitworth, J.L.; Jusko, A.; Li, C.; Wood, N.A.; Willingham, J.; et al. Reduction and Anticancer Activity of Platinum(IV) Complexes. Inorg. Chem. 1998, 37, 2500-2504. [CrossRef]

35. Deo, K.M.; Sakoff, J.; Gilbert, J.; Zhang, Y.; Aldrich Wright, J.R. Synthesis, characterisation and influence of lipophilicity on cellular accumulation and cytotoxicity of unconventional platinum(iv) prodrugs as potent anticancer agents. Dalton Trans. 2019, 48, 17228-17240. [CrossRef] [PubMed]

36. Raveendran, R.; Braude, J.P.; Wexselblatt, E.; Novohradsky, V.; Stuchlikova, O.; Brabec, V.; Gandin, V.; Gibson, D. Pt(iv) derivatives of cisplatin and oxaliplatin with phenylbutyrate axial ligands are potent cytotoxic agents that act by several mechanisms of action. Chem. Sci. 2016, 7, 2381-2391. [CrossRef]

37. Boussios, S.; Mikropoulos, C.; Samartzis, E.; Karihtala, P.; Moschetta, M.; Sheriff, M.; Karathanasi, A.; Sadauskaite, A.; Rassy, E.; Pavlidis, N. Wise management of ovarian cancer: On the cutting edge. J. Pers. Med. 2020, 10, 41. [CrossRef] [PubMed]

38. Yang, M.H.; Kim, J.; Khan, I.A.; Walker, L.A.; Khan, S.I. Nonsteroidal anti-inflammatory drug activated gene-1 (NAG-1) modulators from natural products as anti-cancer agents. Life Sci. 2014, 100, 75-84. [CrossRef] [PubMed]

39. Kostrhunova, H.; Petruzzella, E.; Gibson, D.; Kasparkova, J.; Brabec, V. An Anticancer Pt IV Prodrug That Acts by Mechanisms Involving DNA Damage and Different Epigenetic Effects. Chem. A Eur. J. 2019, 25, 5235-5245. [CrossRef]

40. Nalla, A.K.; Gorantla, B.; Gondi, C.S.; Lakka, S.S.; Rao, J.S. Targeting MMP-9, uPAR, and cathepsin B inhibits invasion, migration and activates apoptosis in prostate cancer cells. Cancer Gene Ther. 2010, 17, 599-613. [CrossRef]

41. Sun, W.; Chen, G. Impact and mechanism of non-steroidal anti-inflammatory drugs combined with chemotherapeutic drugs on human lung cancer-nude mouse transplanted tumors. Oncol. Lett. 2016, 11, 4193-4199. [CrossRef] [PubMed]

42. Mu, C.Y.; Huang, J.A.; Chen, Y.; Chen, C.; Zhang, X.G. High expression of PD-L1 in lung cancer may contribute to poor prognosis and tumor cells immune escape through suppressing tumor infiltrating dendritic cells maturation. Med. Oncol. 2011, 28, 682-688. [CrossRef]

43. Lin, W.W.; Karin, M. A cytokine-mediated link between innate immunity, inflammation, and cancer. J. Clin. Investig. 2007, 117, 1175-1183. [CrossRef] [PubMed]

44. Tetko, I.V.; Varbanov, H.P.; Galanski, M.; Talmaciu, M.; Platts, J.A.; Ravera, M.; Gabano, E. Prediction of logP for Pt(II) and Pt(IV) complexes: Comparison of statistical and quantum-chemistry based approaches. J. Inorg. Biochem. 2016, 156, 1-13. [CrossRef] [PubMed]

45. Oldfield, S.P.; Hall, M.D.; Platts, J.A. Calculation of lipophilicity of a large, diverse dataset of anticancer platinum complexes and the relation to cellular uptake. J. Med. Chem. 2007, 50, 5227-5237. [CrossRef]

46. Ding, X.J.; Zhang, R.; Liu, R.P.; Song, X.Q.; Qiao, X.; Xie, C.Z.; Zhao, X.H.; Xu, J.Y. A class of Pt(iv) triple-prodrugs targeting nucleic acids, thymidylate synthases and histone deacetylases. Inorg. Chem. Front. 2020, 7, 1220-1228. [CrossRef]

47. Petruzzella, E.; Braude, J.P.; Aldrich-Wright, J.R.; Gandin, V.; Gibson, D. A Quadruple-Action Platinum(IV) Prodrug with Anticancer Activity Against KRAS Mutated Cancer Cell Lines. Angew. Chem. Int. Ed. 2017, 56, 11539-11544. [CrossRef] [PubMed] 
48. Zhang, R.; Song, X.Q.; Liu, R.P.; Ma, Z.Y.; Xu, J.Y. Fuplatin: An Efficient and Low-Toxic Dual-Prodrug. J. Med. Chem. 2019, 62, 4543-4554. [CrossRef]

49. Hu, W.; Fang, L.; Hua, W.; Gou, S. Biotin-Pt (IV)-indomethacin hybrid: A targeting anticancer prodrug providing enhanced cancer cellular uptake and reversing cisplatin resistance. J. Inorg. Biochem. 2017, 175, 47-57. [CrossRef]

50. Petruzzella, E.; Sirota, R.; Solazzo, I.; Gandin, V.; Gibson, D. Triple action Pt(iv) derivatives of cisplatin: A new class of potent anticancer agents that overcome resistance. Chem. Sci. 2018, 9, 4299-4307. [CrossRef]

51. Karmakar, S.; Kostrhunova, H.; Ctvrtlikova, T.; Novohradsky, V.; Gibson, D.; Brabec, V. Platinum(IV)-Estramustine Multiaction Prodrugs Are Effective Antiproliferative Agents against Prostate Cancer Cells. J. Med. Chem. 2020, 63, 13861-13877. [CrossRef] [PubMed]

52. Adams, J.M.; Cory, S. Life-or-death decisions by the Bcl-2 protein family. Trends Biochem. Sci. 2001, 26, 61-66. [CrossRef]

53. Blobaum, A.L.; Uddin, M.J.; Felts, A.S.; Crews, B.C.; Rouzer, C.A.; Marnett, L.J. The 2'-trifluoromethyl analogue of indomethacin is a potent and selective COX-2 inhibitor. ACS Med. Chem. Lett. 2013, 4, 486-490. [CrossRef] [PubMed]

54. Sárosi, M.B. Binding of indomethacin methyl ester to cyclooxygenase-2. A computational study. J. Mol. Model. 2018, 24. [CrossRef] [PubMed]

55. Ferriero, R.; Iannuzzi, C.; Manco, G.; Brunetti-pierri, N. Differential inhibition of PDKs by phenylbutyrate and enhancement of pyruvate dehydrogenase complex activity by combination with dichloroacetate. J. Inherit. Metab. Dis. 2015, 38, 895-904. [CrossRef]

56. Liberti, M.V.; Locasale, J.W. The Warburg Effect: How Does it Benefit Cancer Cells? Trends Biochem. Sci. 2016, 41, 211-218. [CrossRef]

57. Diyabalanage, H.V.K.; Granda, M.L.; Hooker, J.M. Combination therapy: Histone deacetylase inhibitors and platinum-based chemotherapeutics for cancer. Cancer Lett. 2013, 329, 1-8. [CrossRef]

58. Samartzis, E.P.; Labidi-Galy, S.I.; Moschetta, M.; Uccello, M.; Kalaitzopoulos, D.R.; Perez-Fidalgo, J.A.; Boussios, S. Endometriosisassociated ovarian carcinomas: Insights into pathogenesis, diagnostics, and therapeutic targets-A narrative review. Ann. Transl. Med. 2020, 8, 1712. [CrossRef]

59. Nunes, A.S.; Barros, A.S.; Costa, E.C.; Moreira, A.F.; Correia, I.J. 3D tumor spheroids as in vitro models to mimic In vivo human solid tumors resistance to therapeutic drugs. Biotechnol. Bioeng. 2019, 116, 206-226. [CrossRef]

60. Ham, S.L.; Joshi, R.; Luker, G.D.; Tavana, H. Engineered Breast Cancer Cell Spheroids Reproduce Biologic Properties of Solid Tumors. Adv. Healthc. Mater. 2016, 5, 2788-2798. [CrossRef]

61. Yao, H.; Xu, Z.; Li, C.; Tse, M.K.; Tong, Z.; Zhu, G. Synthesis and Cytotoxic Study of a Platinum(IV) Anticancer Prodrug with Selectivity toward Luteinizing Hormone-Releasing Hormone (LHRH) Receptor-Positive Cancer Cells. Inorg. Chem. 2019, 58, 11076-11084. [CrossRef] [PubMed]

62. Ruggieri, V.; Agriesti, F.; Scrima, R.; Laurenzana, I.; Perrone, D.; Tataranni, T.; Mazzoccoli, C.; Muzio, L.L.; Capitanio, N.; Piccoli, C. Dichloroacetate, a selective mitochondria-targeting drug for oral squamous cell carcinoma: A metabolic perspective of treatment. Oncotarget 2015, 6, 1217-1230. [CrossRef]

63. Then, C.K.; Liu, K.H.; Liao, M.H.; Chung, K.H.; Wang, J.Y.; Shen, S.C. Antidepressants, sertraline and paroxetine, increase calcium influx and induce mitochondrial damage-mediated apoptosis of astrocytes. Oncotarget 2017, 8, 115490-115502. [CrossRef]

64. Jordan, A.; Hadfield, J.A.; Lawrence, N.J.; Mcgown, A.T. Anticancer Drugs: Agents Which Interact with the Mitotic Spindle. Med. Res. Rev. 1998, 18, 259-296. [CrossRef]

65. Steinmetz, M.O.; Prota, A.E. Microtubule-Targeting Agents: Strategies To Hijack the Cytoskeleton. Trends Cell Biol. 2018, 28, 776-792. [CrossRef] [PubMed]

66. Huang, X.; Huang, R.; Gou, S.; Wang, Z.; Liao, Z.; Wang, H. Combretastatin A-4 Analogue: A Dual-Targeting and Tubulin Inhibitor Containing Antitumor Pt(IV) Moiety with a Unique Mode of Action. Bioconjug. Chem. 2016, 27, 2132-2148. [CrossRef]

67. Huang, X.; Huang, R.; Gou, S.; Wang, Z.; Liao, Z.; Wang, H. Platinum(IV) complexes conjugated with phenstatin analogue as inhibitors of microtubule polymerization and reverser of multidrug resistance. Bioorganic Med. Chem. 2017, 25, 4686-4700. [CrossRef] [PubMed]

68. Din, F.V.N.; Valanciute, A.; Houde, V.P.; Zibrova, D.; Green, K.A.; Sakamoto, K.; Alessi, D.R.; Dunlop, M.G. Aspirin inhibits mTOR signaling, activates AMP-activated protein kinase, and induces autophagy in colorectal cancer cells. Gastroenterology 2012, 142, 1504-1515. [CrossRef] [PubMed] 